\title{
Effect of Ti/Cr content on the microstructures and hydrogen storage properties of Laves phase-related body-centered-cubic solid solution alloys
}

\author{
K. Young ${ }^{*}$, , D.F. Wong ${ }^{1,2}$, L. Wang ${ }^{1}$ \\ ${ }^{1}$ BASF/Battery Materials-Ovonic, 2983 Waterview Drive, Rochester Hills, MI 48309, \\ USA \\ ${ }^{2}$ Department of Chemical Engineering and Materials Science, Wayne State University, \\ MI 48202, USA
}

Abstract

A series of $\mathrm{BCC} / \mathrm{C} 14$ mixed phase alloys with the chemical composition of $\mathrm{Ti}_{13.6+x} \mathrm{Zr}_{2.1} \mathrm{~V}_{44} \mathrm{Cr}_{13.2-x} \mathrm{Mn}_{6.9} \mathrm{Fe}_{2.7} \mathrm{Co}_{1.4} \mathrm{Ni}_{15.7} \mathrm{Al}_{0.3}, x=0,2,4,6,8,10$, and 12, was fabricated, and their structural, gaseous phase and electrochemical hydrogen storage properties were studied. Raising the maximum pressure for measuring the gaseous hydrogen storage capacity allowed these alloys to reach full activation, and the maximum discharge capacities ranged from 375 to $463 \mathrm{mAh} \mathrm{g}^{-1}$. As the $\mathrm{Ti} / \mathrm{Cr}$ ratio in the alloy composition increased, the maximum gaseous hydrogen storage capacity improved due to the expansion in both BCC and $\mathrm{C} 14$ unit cells. However, reversibility decreased due to the higher stability of the hydride phase, as indicated by the lower equilibrium pressures measured for these alloys. As with most other metal hydride alloys, the electrochemical

\footnotetext{
* Corresponding author Tel: +1 248293 7000; fax: +1 248299 4520. E-mail address: kwo.young@basf.com (K. Young).
} 
capacities measured at 50 and $4 \mathrm{~mA} \mathrm{~g}^{-1}$ fell between the boundaries set by the maximum and reversible gaseous hydrogen storage capacities. The poorer high-rate dischargeability observed with higher $\mathrm{Ti} / \mathrm{Cr}$ ratios was attributed to the lower surface exchange current (less catalytic). Two other negative impacts observed with higher Ti/Cr ratios in the alloy composition are poorer cycle stability and lower open-circuit voltage.

Keywords: Hydrogen absorbing alloys; Metal hydride electrode; Laves phase alloys; Body-centered-cubic alloys; Activation. 


\section{Introduction}

The nickel/metal hydride $(\mathrm{Ni} / \mathrm{MH})$ battery is a mature technology used mainly in the consumer retail market as a direct replacement for primary alkaline and $\mathrm{Ni}-\mathrm{Cd}$ rechargeable batteries. The success of the $\mathrm{Ni} / \mathrm{MH}$ battery in the automobile industry has recently enabled more than six million hybrid electrical vehicles sold worldwide.

However, due to its limited gravimetric energy density $\left(<110 \mathrm{Wh} \mathrm{kg}^{-1}\right)$, the current state of the $\mathrm{Ni} / \mathrm{MH}$ battery loses market share in the portable electronic devices and the battery-powered electrical vehicle markets to the lighter Li-ion technology. As such, the next generation of $\mathrm{Ni} / \mathrm{MH}$ batteries is geared toward improving two main targets: raising the energy density and lowering cost. There are many research activities in the positive electrode, negative electrode, and electrolyte areas aimed toward improving energy density. The most convenient approach is to replace the metal hydride $(\mathrm{MH})$ alloy in the negative electrode with alternative alloys that offer higher capacities. Current Ni/MH batteries use rare-earth-metal-based $\mathrm{AB}_{5}$ alloys that have $\sim 320 \mathrm{mAh} \mathrm{g}^{-1}$ capacity. Among the candidates, superlattice $\mathrm{A}_{2} \mathrm{~B}_{7}\left(350 \mathrm{mAh} \mathrm{g}^{-1}[1]\right)$ and Laves-phase based $\mathrm{AB}_{2}(440$ $\left.\mathrm{mAh}^{-1},[2]\right)$ alloys are the most promising alloy alternatives with a good balance between high-rate dischargeability (HRD), cycle life, charge retention, activation, self discharge, and applicable temperature range. Other $\mathrm{MH}$ alloys have the potential to reach even higher capacities. For instance, a Ti-V-Cr alloy with a body-centered-cubic (BCC) structure can store up to $3.5 \mathrm{wt} . \%$ of hydrogen in the gaseous phase, which is equivalent to an electrochemical capacity of $938 \mathrm{mAh} \mathrm{g}^{-1}[3]$. However, the pure BCC MH alloy has 
very poor electrochemical properties [4]. In order to facilitate electrochemical reaction, a Laves phase with similar chemical make-up was added to the BCC alloy [5]. The formal name of this mixed phase alloy is "Laves phase-related BCC solid solution" named by Iba and Akiba [6, 7]. This family of $\mathrm{MH}$ alloys has a two-phase microstructure composed of a $\mathrm{BCC}$ phase and a Laves phase (mostly $\mathrm{C} 14$ ) with a general formula of $\mathrm{AB}_{x}$, where $\mathrm{A}$ is an element or any combination of elements from Group 4A (mostly Ti), B is from Group 5A, 6A, or 7A (mainly V), and $x$ is between 1 and 6 . The high density of phase boundaries makes it possible to combine the advantages of BCC (high hydrogen storage capability [4, 8]) and C14 phases (good absorption kinetics [9], easy formation due to its brittleness $[5,10,11]$, and high surface catalytic activity [12]) by increasing the synergetic effect between the two phases. The density of phase boundaries also promotes the formation of coherent and catalytic interfaces at the boundaries, improving hydrogen absorption [13]. Many reports in the area of thermal annealing and partially compositional substitution are available [14-26]

Our first set of studies in Laves phase-related BCC solid solution MH alloys began with a series of samples that yielded BCC/C14 ratios ranging from 0.09 to 8.52 [27]. The structural, gaseous phase and electrochemical hydrogen storage properties were reported. One interesting finding: the electrochemical discharge capacities of these alloys were low (155-172 $\left.\mathrm{mAh} \mathrm{g}^{-1}\right)$ and did not fall between the maximum and reversible hydrogen storage capacities measured in the gaseous phase, which are very different from other $\mathrm{MH}$ alloys used in electrochemical applications. In continuation of the effort to raise $\mathrm{Ni} / \mathrm{MH}$ battery energy density and to address the low electrochemical capacities 
from the previous study, results from a second series of alloys with varying $\mathrm{Ti} / \mathrm{Cr}$ ratio targeting higher capacity, as well as a new activation process, are presented in this paper.

\section{Experimental details}

Arc melting was performed under continuous argon flow with a non-consumable tungsten electrode and a water-cooled copper tray. Before each run, a piece of sacrificial titanium underwent several melting-cooling cycles to reduce the residual oxygen concentration in the system. Each 12-g ingot was re-melted and turned over several times to ensure uniformity in the chemical composition. Chemical composition for the ingot was analyzed using a Varian Liberty 100 inductively coupled plasma optical emission spectrometer (ICP-OES). A Philips $X^{\prime}$ Pert Pro x-ray diffractometer (XRD) was used to study the microstructure, and a JEOL-JSM6320F scanning electron microscope (SEM) with energy dispersive spectroscopy (EDS) capability was used to study the phase distribution and composition. Gaseous phase hydrogen storage characteristics for each sample were measured using a Suzuki-Shokan multi-channel pressure-concentrationtemperature (PCT) system. In the PCT analysis, each sample (a single piece of ingot with a newly cleaved surface and a weight of about $2 \mathrm{~g}$ ) was first activated by a 2-h thermal cycle between $300^{\circ} \mathrm{C}$ and room temperature at 2.5 and $5 \mathrm{MPa} \mathrm{H}_{2}$ pressure for alloys P8*, P8-P14, respectively. PCT isotherms at 30,60 , and $90^{\circ} \mathrm{C}$ were then measured. Details of the electrode preparations have been reported previously [28, 29]. In the flooded capacity study performed at room temperature, the electrode samples were not activated in a hot alkaline solution bath, such was typical of the $\mathrm{AB}_{2} \mathrm{MH}$ alloys [29]. The electrode 
samples were first charged with a constant current of $50 \mathrm{~mA} \mathrm{~g}^{-1}$ for $10 \mathrm{~h}$ and then discharged with a current of $50 \mathrm{~mA} \mathrm{~g}^{-1}$ until a $0.9 \mathrm{~V}$ cutoff voltage against a pre-activated sintered $\mathrm{Ni}(\mathrm{OH})_{2}$ counter electrode was reached, followed by two low rate discharge pulls at 12 and $4 \mathrm{~mA} \mathrm{~g}^{-1}$, respectively.

\section{Results and discussion}

\subsection{Alloy Composition}

Seven alloys with a general formula of

$\mathrm{Ti}_{13.6+x} \mathrm{Zr}_{2.1} \mathrm{~V}_{44} \mathrm{Cr}_{13.2-x} \mathrm{Mn}_{6.9} \mathrm{Fe}_{2.7} \mathrm{Co}_{1.4} \mathrm{Ni}_{15.7} \mathrm{Al}_{0.3}, x=0,2,4,6,8,10$, and 12

were prepared by arc melting for this study. Design compositions of these alloys and the $\mathrm{B} / \mathrm{A}$ ratio are listed in Table 1. The first alloy (P8) of this series (P8-P14) with $x=0$ shares the same composition of the last alloy of the previous series (P1-P8) and demonstrated the highest electrochemical discharge capacity out of the alloys P1-P8 [27]. The P8-P14 series of alloys has incrementally increasing Ti-content at the expense of $\mathrm{Cr}$. Variation in Ti-Cr content in this BCC-C14 MH alloy family has not been studied before. A study from $\mathrm{Yu}$ and his coworkers does report that the partial replacement of $\mathrm{Cr}$ by $\mathrm{Mn}$ increases the discharge capacity at the cost of the cycle stability [40].

ICP results from the ingot samples are listed in Table 1, and the compositions fall close to their target values. The previous series of alloys showed unevenness in $\mathrm{Cr}$ content, and this has been improved by increasing the power during arc melting. The 
measured $\mathrm{B} / \mathrm{A}$ ratio of this series of alloys (P8-P14) varies from 2.61 to 5.36, and the range is similar to the previous series (P1-P8).

3.2 XRD structure analysis

XRD patterns of the seven alloys are shown in Fig. 1. Two sets of diffraction peaks, $\mathrm{C} 14$ and BCC, are observed. As the Ti-content in the alloy increases, the BCC peaks decrease in intensity and shift to lower angles, and the $\mathrm{C} 14$ peaks increase in intensity and shift in the same direction as the BCC peaks. Lattice constants of both phases calculated from the XRD patterns are listed in Table 2 and plotted in Fig. 2. As the amount of Ti increases, lattice constants $a$ and $c$ for the $\mathrm{C} 14$ phase and lattice constant $a$ for the BCC phase increase. In $\mathrm{C} 14$ phase, the $c / a$ ratio increases, stabilizes, and decreases as the Ti-content increases in the series of alloys. The anisotropic growth of the C14 unit cell arises from the partial replacement of B-site $\mathrm{Cr}$ (metallic radius in $\mathrm{AB}_{2}$ intermetallic alloy of $1.423 \AA$ [31]) with the relatively larger A-site Ti (radius of $1.614 \AA$ [31]) and will be discussed alongside the evolution of the chemical composition in the C14 phase in the SEM/EDS section. Lattice constant $a$ in BCC phase increases from 2.9683 to $3.0165 \AA$ as the Ti-content in the alloy increases. Although these BCC lattice constants are smaller than the optimized value of $3.042 \AA$ for maximized hydrogen storage capacity [32], they are an improvement over values reported in the previous study (2.9568 to $2.9664 \AA$ [27]). 
Phase abundance and crystallite sizes of each phase are listed in Table 2. These values were obtained from full pattern fitting of the XRD data using the Rietveld method and Jade 9 software. Since the complete overlapping of peaks between TiNi B2 cubic phase and $\mathrm{BCC}$ phase, only $\mathrm{BCC}$ and $\mathrm{C} 14$ phases were taken into the calculation for the current study. As the Ti-content in the alloy increases, the abundance of C14 phase increases from 11.0 to $56.4 \mathrm{wt} . \%$ and drops slightly to $52.5 \mathrm{wt} . \%$ in the last alloy of this series. The $\mathrm{BCC}$ phase shows this trend in reverse: dropping from $89.0 \%$ to $47.5 \%$. At the same time, the $\mathrm{C} 14$ crystallite size first increases and then decreases, while the BCC crystallite size decreases monotonically. While the trend in crystallite sizes in the C14 phase is similar to the previous series of alloys when ordered for increasing $\mathrm{BCC} / \mathrm{C} 14$ ratio, the trend in crystallite sizes in the $\mathrm{BCC}$ phase is in the reverse direction of the previous study [27]. The crystallite size in the previous series was shown to have a close correlation to bulk hydrogen diffusion [27].

\subsection{SEM/EDS microstructure analysis}

Microstructures for this series of alloys were studied using SEM, and the backscattering electron images (BEI) are presented in Fig. 3. Chemical compositions of areas showing different contrast levels were studied by EDS analysis, and the results are summarized in Table 3. During cooling, BCC phase with high V-content solidifies first to form a three-dimensional framework while the rest of the liquid solidifies into Laves phase as the alloy cools further. Darker regions in the SEM micrographs are BCC phase (lower average atomic mass due to lower $\mathrm{Zr}$-content) and represent the intersection of a 
plane and a three-dimensional framework with three major axes perpendicular to each other. Inside the $\mathrm{C} 14$ region, some of the gray areas include the $\mathrm{TiNi} / \mathrm{Zr}_{\mathrm{x}} \mathrm{Ni}_{\mathrm{y}}$ phase. This $\mathrm{TiNi} / \mathrm{Zr}_{x} \mathrm{Ni}_{y}$ mixed phase is a product of solid-state transformation after the Laves phase has solidified $[33,34]$. In a previous study, TiNi phase was found to increase the capacity but lower the HRD [35]. As the Ti-content increases in the alloy, the grain sizes of the BCC and $\mathrm{C} 14$ phases both decrease and then increase. Un-reacted metallic $\mathrm{Zr}$ was found in the first few alloys (Fig. 3a spot 5, abbrev. as 3a-5, 3b-5, 3c-4). BCC phase contains almost no $\mathrm{Zr}$, and most of the $\mathrm{Zr}$ goes into the $\mathrm{C} 14$ phase. As the Ti-content increases in the alloy, the C14 phase abundance increases and thus less un-alloyed $\mathrm{Zr}$ can be found in the final sample.

Compositions of C14 phase determined by EDS are listed in italics in Table 3. In the calculation of B/A stoichiometry, $\mathrm{V}$ is assumed to occupy the B-site according to a previous study of V-substitution in a series of C14 MH alloys [36]. The Zr-, Ti-, V-, Nicontents and the B/A ratio in C14 phase are plotted in Fig. 4a. As the overall Ti-content in the alloy increases, the Ti-content in the $\mathrm{C} 14$ phase increases linearly while $\mathrm{Zr}$-content decreases; the Ni-content decreases and then stabilizes; the V-content stays about level; and the B/A ratio falls monotonically from 2.1 to 1.5 . From a previous study, we know that the stoichiometry of $\mathrm{AB}_{2} \mathrm{MH}$ alloy covers a wide range of values (B/A from 1.5 to 4.0), and it influences the electrochemical properties [37]. When Ti partially replaces $\mathrm{Zr}$ in the A-site, both lattice constants $a$ and $c$ decrease due to the smaller size of Ti [28]. In this study, increasing $\mathrm{Ti}$ at the expense of $\mathrm{Ni}$ and $\mathrm{Zr}$ increases both $a$ and $c$ in the $\mathrm{C} 14$ unit cell (Fig. 2) due to the decrease in the B/A ratio [38]. The increase in Ti-content in 
the $\mathrm{C} 14$ phase is at a rate faster than the decrease in $\mathrm{Zr}$-content, which results in a net increase in $\mathrm{Ti}+\mathrm{Zr}$ (total $\mathrm{A}$-site atoms) and a decrease in $\mathrm{B} / \mathrm{A}$ ratio. Although the total amount of $\mathrm{Zr}$ in the alloy remains the same in this series of alloys, the $\mathrm{Zr}$-content in the C14 phase decreases due to the increase in $\mathrm{C} 14$ phase abundance at the expense of the $\mathrm{Zr}$ free BCC phase. Comparing the evolution of the lattice constants (Fig. 2) and the compositions in C14 phase (Fig. 4a), we found a direct correlation between Ni-content and lattice constant $c$. C14 crystal structure is composed of alternating A2B and B3 layers along the $c$-axis (Fig. 5). There are two sites for B-atoms $-2 a$ on the A2B layer and $6 h$ on the B3 layer. The substitution of B-atoms in the $6 h$ site will only change the $c$ lattice constant since the $a$ lattice constant depends more on the composition of the more crowded A2B layer ( $2 a$ and $4 f$ sites). Our hypothesis supposes that $\mathrm{Ni}$-content in the $\mathrm{C} 14$ phase correlates well to the $c$ lattice constant due to the nature of the $6 h$ site, which is occupied mainly by $\mathrm{Ni}$ atoms with the smallest radius.

Compositions of BCC phase determined by EDS are listed in bold in Table 3. The Ti-, V-, Cr-, and Mn-contents in BCC phase are plotted against the Ti-content in the alloy in Fig. 4b. As the overall Ti-content and C14 abundance increase in the alloy, the Ti- and V-content increase, $\mathrm{Cr}$-content decrease, and $\mathrm{Mn}$ - and Ni-contents remain about the same. The decrease in $\mathrm{Cr}$ and the increase in $\mathrm{Ti}$ are from the changes in overall composition, and they cause the unit cell to expand slightly due to the larger size of Ti. The Ti-content in the BCC phase from the current study (6.1 to 14.8 at.\%) are higher than the BCC phases formed in the alloys from the previous study (4.7 to 5.8 at.\%), but the Ti-content is still below an alloy with 28.4 at.\% Ti in the BCC phase that demonstrated the highest 
storage capacity [32]). Therefore, in order to increase the storage capacity of the BCC phase, more Ti has to be added into the formula. In the BCC phase, the increase in the Ticontent at the expense of $\mathrm{Cr}$-content causes a lattice expansion as seen in the larger lattice constants in the XRD analysis (Table 2). The $\mathrm{V} /(\mathrm{Ti}+\mathrm{Cr}$ ) ratio in the design is constant (1.64), but the ratio in BCC phase as shown in Fig. 4b increases from 2.3 to 3.9. Since a large portion of $\mathrm{V}$ goes into $\mathrm{BCC}$ phase, it follows that the decrease in $\mathrm{BCC}$ phase abundance (Table 2) increases the $\mathrm{V} /(\mathrm{Ti}+\mathrm{Cr}$ ) ratio in the $\mathrm{BCC}$ phase.

\subsection{Gaseous hydrogen storage properties}

Gaseous phase hydrogen storage properties of the alloys were studied by PCT. All samples are activated within one thermal cycle in the presence of hydrogen at the maximum pressure (5.0 MPa). Consequent cycles did not change the PCT characteristics significantly. The resulting absorption and desorption isotherms measured at 30 and $60^{\circ} \mathrm{C}$ are shown in Fig. 6. Sample P8* was activated and measured at a maximum hydrogen pressure of 1.1 MPa while all other samples were measured up to $5 \mathrm{MPa}$. The advantages of higher hydrogen pressure are clear: it allows completion of the $2^{\text {nd }}$ pressure plateau on the PCT curve, less hysteresis, and better reversibility. Information obtained from the PCT study is summarized in Table 4. Equilibrium pressures in the desorption curves at 1.3 and $1.5 \mathrm{wt} . \%$ hydrogen storage were used as the plateau pressure for alloys P8-P10 and alloys P11-P14, respectively; and they show a decreasing trend with the increase in Ti-content. The lower equilibrium pressure arises from the expanded unit cells in both BCC and C14 phases. Hysteresis of the PCT isotherm is defined as $\ln \left(P_{\mathrm{a}} / P_{\mathrm{d}}\right)$, where $P_{\mathrm{a}}$ 
and $P_{\mathrm{d}}$ are the absorption and desorption equilibrium pressures at the stated hydrogen storage concentrations, respectively. In general, the hysteresis decreases as the Ti-content increases, which is expected to increase the cycle stability by reducing the pulverization during cycling [39]. As the Ti-content increases, the maximum hydrogen storage capacity increases due to the size of the larger unit cell and its capability to accommodate more hydrogen; but the reversible hydrogen storage capacity decreases due to the increase in the metal-hydrogen bond strength (judging from the lower equilibrium pressure). The desorption equilibrium pressures at 30,60 , and $90^{\circ} \mathrm{C}$ were used to estimate the changes in enthalpy $(\Delta H)$ and entropy $(\Delta S)$ by the equation

$$
\Delta G=\Delta H-T \Delta S=R T \ln P
$$

where $R$ is the ideal gas constant and $T$ is the absolute temperature. Results of these calculations are listed in Table 4. The values may not be accurate and can only be used for comparison among these alloys. As the Ti-content in the alloys increases, both $-\Delta H$ and $-\Delta S$ first decrease and then increase. The $\Delta H$ value does not correlate with the plateau pressure, which is rarely observed in alloys with a single dominant phase. The $\Delta S$ is an indication of how far the MH system is from a perfect, ordered state (degree of disorder). The theoretical value of $\Delta S$ is the entropy of hydrogen gas, which is close to $-135 \mathrm{~J} \mathrm{~mol}^{-1} \mathrm{~K}^{-1}$. It is interesting to see that the alloys with more equal $\mathrm{C} 14$ and $\mathrm{BCC}$ phase abundances (P13 and P14) do not have the highest $\Delta S$ value. Instead, alloys P10 and P11, with a high density of BCC/C14 grain boundaries (as seen from the SEM micrograph in Fig. 3) have the highest $\Delta S$. 


\subsection{Electrochemical properties}

Discharge capacities of each alloy was measured in a flooded-cell configuration against a partially pre-charged $\mathrm{Ni}(\mathrm{OH})_{2}$ positive electrode. No alkaline pretreatment was applied before the half-cell measurement. Each sample electrode was charged at a constant current density of $50 \mathrm{~mA} \mathrm{~g}^{-1}$ for $10 \mathrm{~h}$ and then discharged at a current density of $50 \mathrm{~mA} \mathrm{~g}^{-1}$ followed by two pulls at 12 and $4 \mathrm{~mA} \mathrm{~g}^{-1}$. The full capacities $\left(4 \mathrm{~mA} \mathrm{~g}^{-1}\right)$ from the first 13 cycles are plotted in Fig. 7a to study the activation and cycling behavior of these alloys. The activation of the alloys becomes easier with the decrease in BCC phase abundance and the lower $\mathrm{Cr}$-content due to the corrosion resistance of $\mathrm{BCC}$ phase compared to $\mathrm{C} 14$ phase [40] and the corrosion resistance of $\mathrm{Cr}$ against $\mathrm{KOH}$ [41]. Reduction in the corrosion resistance helps activation; however, it also reduces cycle stability [30]. The cycle stability also deteriorates with an increase in $\mathrm{Ti} / \mathrm{Cr}$ ratio due the higher presence of $\mathrm{Ti}$, which is easily corroded in $\mathrm{KOH}$ electrolyte, while the lower $\mathrm{Cr}$ presence reduces the surface protection from corrosion [42]. The other source of capacity degradation may arise from severe surface cracking that exposes new surfaces to oxidation, which is seen in pure BCC-phase MH alloys [43]. Further structural analyses are needed to identify the failure mechanism. The tradeoff of higher discharge capacity for poorer cycle performance with increasing $\mathrm{Ti} / \mathrm{Cr}$ ratio follows a similar conclusion from a previous report studying decreasing $\mathrm{Cr} / \mathrm{Mn}$ ratio in a series of $\mathrm{BCC} / \mathrm{C} 14$ alloys [30]. Capacities from 50 and $4 \mathrm{~mA} \mathrm{~g}^{-1}$ discharge rates measured at the $4^{\text {th }}$ and $2^{\text {nd }}$ cycle, respectively, are listed in Table 5. Both capacities increase and then decrease with 
increasing overall Ti-content. The highest discharge capacity, $463 \mathrm{mAh} \mathrm{g}^{-1}$, was measured with alloy P12. The evolution in electrochemical capacity with Ti-content must balance the expanding unit cell (gain) with lower plateau pressure (loss). When the gaseous hydrogen storage capacity is converted to a theoretical electrochemical capacity and plotted against Ti-content alongside the measured electrochemical storage capacities, the $4 \mathrm{~mA} \mathrm{~g}^{-1}$ (low rate) curve tracks the maximum gaseous hydrogen storage capacity and the $50 \mathrm{~mA} \mathrm{~g}^{-1}$ (high rate) curve tracks the reversible gaseous hydrogen storage capacities (Fig. 8). In this plot, the gaseous hydrogen storage capacity is converted to electrochemical capacity by

$$
1 \text { wt. } \% \text { of } \mathrm{H}_{2}=268 \mathrm{mAh} \mathrm{g}^{-1}
$$

The electrochemical capacities of this series of alloys fall between the boundaries set by the maximum and reversible gaseous hydrogen storage capacities similar to other $\mathrm{MH}$ systems after subjecting the samples to full activation by the $5 \mathrm{MPa}$ hydrogenation process. The low electrochemical capacities measured in the previous study [27] were caused by the incomplete activation of the samples, as can be seen from the low capacity in $\mathrm{P} 8 *$.

Half-cell HRD values of each alloy, defined as the ratio of discharge capacity measured at $50 \mathrm{~mA} \mathrm{~g}^{-1}$ to that measured at $4 \mathrm{~mA} \mathrm{~g}^{-1}$, are measured at the stabilized $4^{\text {th }}$ cycle and listed in Table 5. Except for P10, HRDs of all alloys are stabilized within 4 cycles. As the Ti-content in the alloy increases, HRD decreases rapidly. The increase in 
the catalytic $\mathrm{C} 14$ phase abundance does not help the HRD performance. Comparing the HRD of P8* and P8, we find that the electrochemical HRD in P8* is higher despite the incomplete activation and its lower reversibility in the gaseous phase (Fig. 6a). We can attribute this observation to the different phases in the alloys. The two pressure plateaus observed in the PCT curves can be associated with two different phases. The first phase with lower plateau pressure (from 0.3 to $1.0 \mathrm{wt.} \%$ in Fig. 6a) has better rate capability than the second phase (from 1.0 to 1.6 wt.\% in Fig. 6a). According to literature, C14 phase is more catalytic than BCC phase [9]. Therefore, we assign the phase with lower plateau pressure to the $\mathrm{C} 14$ phase and the phase with higher plateau pressure to the $\mathrm{BCC}$ phase. The increasing range of the first plateau is consistent with the increase in C14 phase abundance, and the decreasing range of the second plateau is consistent with the decrease in BCC phase abundance derived in the XRD analysis (Table 2). So while C14 phase does contribute to rate capability, we analyze the heats of hydride formation of each phase to explain why increasing $\mathrm{C} 14$ phase does not contribute to better HRD performance. The heat of hydride formation of an intermetallic alloy (and of each phase) can be estimated by the heats of hydride formation of the constituent elements [44]:

$$
\Delta H\left(\mathrm{~A}_{\mathrm{m}} \mathrm{B}_{\mathrm{n}}\right) \approx \frac{m}{n+m} \Delta H(\mathrm{~A})+\frac{n}{n+m} \Delta H(\mathrm{~B})
$$

The absolute values of $\Delta H$ from A-elements (hydride formers) are much larger than Belements (modifiers), and so the $\Delta H(\mathrm{~B})$ term can be neglected in the calculations. We use the $\Delta H$ from $\mathrm{Zr}\left(-163 \mathrm{~kJ}^{\mathrm{mol} \mathrm{H}}{ }_{2}^{-1}\right)$, $\mathrm{Ti}\left(-124 \mathrm{~kJ} \mathrm{~mol} \mathrm{H}_{2}^{-1}\right)$, and $\mathrm{V}\left(-34 \mathrm{~kJ} \mathrm{~mol} \mathrm{H}_{2}^{-1}\right)$ to calculate the heats of hydride formation and get an indication of the metal-hydrogen 
bond strengths in $\mathrm{C} 14$ phase and BCC phase for each sample. According to this estimation, the $\mathrm{C} 14$ and $\mathrm{BCC}$ phases in alloy $\mathrm{P} 8$ are about -50 and $-28 \mathrm{~kJ} \mathrm{~mol} \mathrm{H}_{2}{ }^{-1}$, respectively. The $\Delta H$ for $\mathrm{C} 14$ phase is outside the optimal window for room temperature and atmospheric operation $\left(-40\right.$ to $\left.-25 \mathrm{~kJ} \mathrm{~mol} \mathrm{H}_{2}{ }^{-1}\right)$, while the $\Delta H$ for BCC phase is near the upper limit of the window. This indicates that part of the capacity contribution from the $\mathrm{C} 14$ phase is not reversible in the gaseous phase reaction. The increase in Ti-content reduces the $\Delta H$ for each phase even further, for example, -52 and $-30 \mathrm{~kJ} \mathrm{~mol} \mathrm{H}_{2}{ }^{-1}$ for C14 and BCC phases in alloy P9, respectively. In general, the gap between the high-rate and low-rate capacities measured electrochemically is narrower than the capacities measured in the gaseous phase (Fig. 8). The electrochemical reaction has better reversibility due to the catalytic surface oxide formed during the activation process [45]. The appearance of the slow-reacting TiNi phase in the last two alloys (P13 and P14) further hampers high-rate performance.

In order to study the reason for the HRD decrease with increased Ti-content, both bulk diffusion coefficient $(D)$ and surface exchange current $\left(I_{\mathrm{o}}\right)$ were measured electrochemically. The details of both measurements were previously reported [46], and the values are listed in Table 5. In general, the trend of $D$ with Ti-content is not obvious, and the values fall between the $D$ values for $\mathrm{AB}_{2} \mathrm{MH}$ alloys $\left(D \sim 1 \times 10^{-10} \mathrm{~cm}^{2} \mathrm{~s}^{-1}[47]\right)$ and $\mathrm{AB}_{5} \mathrm{MH}$ alloys $\left(D \sim 2.6 \times 10^{-10} \mathrm{~cm}^{2} \mathrm{~s}^{-1}\right.$ [47]). The $I_{\mathrm{o}}$ value decreases with increasing Ti-content. These values indicate that the poor HRD observed in this series of alloys is due to slower surface reaction. Both $\mathrm{AB}_{2}\left(32 \mathrm{~mA} \mathrm{~g}^{-1}\right)$ and $\mathrm{AB}_{5}\left(43 \mathrm{~mA} \mathrm{~g}^{-1}\right) \mathrm{MH}$ alloys [47] have higher $I_{\mathrm{o}}$ values over the alloys with high Ti-content in this study. Substitution 
of $\mathrm{Cr}$ with $\mathrm{Ti}$ in the $\mathrm{BCC}-\mathrm{C} 14$ alloys tends to increase the storage capacity at the expense of HRD performance. Future studies can focus on a method to increase capacity while maintaining high HRD performance.

The $D$ value and the $\mathrm{C} 14$ crystallite size are plotted against the alloy numbers in Fig. 9. The $D$ value tends to increase with increasing Ti-content while the $\mathrm{C} 14$ crystallite size tends to decrease. This general trend is similarly observed in the previous series of BCC-C14 alloys (Fig. 8 in [27]). It indicates that smaller crystallite sizes of catalytic C14 allow the formation of more inter-granular zones that facilitate proton transfer and increase $D$ value.

Open circuit voltage (OCV) for each alloy was measured and listed in Table 5. OCV can be related to the electrode voltage by the Nernst equation. Alloys with higher Ti-content have lower plateau pressure in PCT measurement and therefore have lower OCV. The highest OCV was measured in the partially activated P8* sample. It has been demonstrated that the synergetic effect between phases can effectively bring down the voltage $[48,49]$. The relatively lower capacity and higher OCV in P8* is an indication of an immature phase boundary that is insufficient for electrochemical reaction and transport of hydrogen in the bulk.

\section{Conclusions}


A series of Laves phase-related body-centered-cubic solid solution metal hydride alloys with $\mathrm{BCC} / \mathrm{C} 14$ ratios ranging from 0.9 to 8.1 were studied. The general formula is $\mathrm{Ti}_{13.6+x} \mathrm{Zr}_{2.1} \mathrm{~V}_{44} \mathrm{Cr}_{13.2-x} \mathrm{Mn}_{6.9} \mathrm{Fe}_{2.7} \mathrm{Co}_{1.4} \mathrm{Ni}_{15.7} \mathrm{Al}_{0.3}, x=0,2,4,6,8,10$, and 12. Similar to a previous study that investigated the effects of $\mathrm{Cr} / \mathrm{Mn}$ ratio, the increase in $\mathrm{Ti} / \mathrm{Cr}$ ratio increased the capacity at the expense of cycle stability and high-rate dischargeability. The increases in lattice parameters for BCC and C14 phases increased storage capacity but also increased the stability of the hydride, affecting the reversibility and making discharge more difficult. The main influence on the high-rate performance was through the change of the electrochemically catalytic nature of the surface. We also found that activation of the samples at pressures higher than the second PCT plateau (BCC phase) significantly improved the electrochemical capacity.

\section{Acknowledgement}

This work is financially supported by ARPA-E under the robust affordable next generation EV-storage (RANGE) program (DE-AR0000386). 


\section{References}

[1] T. Ozaki, M. Kanemoto, T. Kakeya, Y. Kitano, M. Kuzuhara, M. Watada, S. Tanase, T. Sakai, J. Alloys Compd. 446-447 (2007) 620-624.

[2] K. Young, R. Regmi, G. Lawes, T. Ouchi, B. Reichman, M.A. Fetcenko, A. Wu, J. Alloys Compd. 490 (2010) 282-292.

[3] Y. Yan, Y. Chen, H. Liang, C. Wu, M. Tao, J. Alloys Compd. 441 (2007) 297300.

[4] X.B. Yu, Z. Wu, B.J. Xia, N.X. Xu, J. Chem. Phys. 121 (2004) 987-990.

[5] H. Iba and E. Akiba, J. Alloys Compd. 231 (1995) 508-512.

[6] H. Iba and E. Akiba, J. Japan Inst. Metals 58 (1994) 1225-1232.

[7] E. Akiba and H. Iba, Intermetallics 6 (1998) 461-470.

[8] H. Inoue, S. Arai, C. Iwakura. Electrochim. Acta 41 (1996) 937-9.

[9] N. Chen, R. Li, Y. Zhu, Y. Liu, H. Pan, Acta Metall. Sinica 40 (2004) 1200-1204.

[10] E. Rönnebro, D. Noréus, T. Sakai, M. Tsukahara, J. Alloys Compd. 231 (1995) 90-94.

[11] M. Tsukahara, K. Takahashi, T. Mishima, A. Isomura, T. Sakai, J. Alloys Compd. 236 (1996) 151-155.

[12] S. Qiu, H. Chu, Y. Zhang, D. Sun, X. Song, L. Sun, F. Xu, J. Alloys Compd. 471 (2009) 453-456.

[13] H. Iba and E. Akiba, J. Alloys Compd. 253-254 (1997) 21-24.

[14] Q.A. Zhang, Y.Q. Lei, C.S. Wang, F.S. Wang, Q.D. Wang, J. Power Sources 75 (1998) 288-291. 
[15] Y. Zhu, H. Pan, M. Gao, Y. Liu, Q. Wang, J. Alloys Compd. 348 (2003) 301-308.

[16] H. Pan, Y. Zhu, M. Gao, Y. Liu, Y. Lei, Q. Wang, J. Alloys Compd. 370 (2004) $271-279$

[17] L. Chen, M. Guo, Y. Lei, R. Li, Q. Wang, Mater. Chem. Phys. 92 (2005) 554-558.

[18] R. Li, H. Pan, M. Gao, Y.Q. Lei, J. Alloys Compd. 432 (2007) 183-188.

[19] H. Pan, R. Li, Y. Liu, M. Gao, H. Miao, Y. Lei, Q.D. Wang, J. Alloys Compd. 463 (2008) 189-195.

[20] M. Gao, S. Zhang, H. Miao, Y. Liu, H. Pan, J. Alloys Compd. 489 (2010) 552557.

[21] S. Suwarno, J.K. Solberg, J.P. Maehlen, B. Krogh, V.A. Yartys, Int. J. Hydrogen Energy 377 (2012) 7624-7628.

[22] Z.M. Hang, X.Z. Xiao, S. Li, H. Ge, C. Chen, L. Chen, J. Alloys Compd. 529 (2013) 128-133.

[23] Z. Hang, X. Xiao, S. Li, H. Ge, C. Chen, L. Chen, J. Alloys Compd. 529 (2012) $128-133$

[24] J. Matsuda, E. Akiba, J. Alloys Compd. 581 (2013) 369-372.

[25] S. Suwarno, J.K. Solberg, J.P. Maehlen, B. Krogh, V.A. Yartys, J. Alloys Compd. 582 (2014) 540-546.

[26] H.Y. Zhou, F. Wang, J. Wang, Z. M. Wang, Q.R. Yao, J.Q. Deng, C.Y. Tang, G.H. Rao, Int. J. Hydrogen Energy 39 (2014) 14887-14895.

[27] K. Young, J. Nei, D.F. Wong, L. Wang, Int. J. Hydrogen Energy, DOI: 10.1016/j.ijhydene.2014.01.134 
[28] K. Young, M.A. Fetcenko, T. Ouchi, F. Li, J. Koch, J. Alloys Compd. 464 (2008) $238-247$.

[29] K. Young, M.A. Fetcenko, J. Koch, K. Morii, T. Shimizu, J. Alloys Compd. 486 (2009) 559-569.

[30] J. Yu, B. Liu, K. Cho, J. Lee, J. Alloys Compd. 278 (1998) 283-290.

[31] K. Young, T. Ouchi, J. Koch, M.A. Fetcenko, J. Alloys Compd. 477 (2009) 749758.

[32] Y. Yan, Y. Chen, H. Liang, X. Zhou, C. Wu. M. Tao, L. Ping, J. Alloys Compd. (454) 2008 427-31.

[33] L.A. Bendersky, L. Wang, W.J. Boettinger, D.E. Newbury, K. Young, B. Chao, Metall. Mater. Trans. A 41 (2010) 1891-906.

[34] W.J. Boettinger, D.E. Newbury, K. Wang, L.A. Bendersky, C. Chiu, U.R. Kattner, K. Young, B. Chao, Metall. Mater. Trans. A 41 (2010) 2033-47.

[35] K. Young, J. Nei, T. Ouchi, M.A. Fetcenko, J. Alloys Compd. 509 (2011) 22772284.

[36] K. Young, M.A. Fetcenko, F. Li, T. Ouchi, J. Koch, J. Alloys Compd. 468 (2009) $482-92$.

[37] K. Young, J. Nei, B. Huang, M.A. Fetcenko, J. Int. Hydrogen Energy 36 (2011) $11146-11154$.

[38] K. Young, T. Ouchi, J. Yang, M.A. Fetcenko, J. Int. Hydrogen Energy 36 (2011) $11137-11145$.

[39] K. Young, T. Ouchi, M.A. Fetcenko, J. Alloys Compd. 480 (2009) 428-433.

[40] K.H. Young, M.A. Fetcenko, S.R. Ovshinsky, T. Ouchi, B. Reichman, W. Mays, in Hydrogen at Surface and Interfaces, ed. G. Jerkiewicz, J.M. Feliu, B.N. Popov, Electrochemical Society Proceeding Vol. 2000-16, p. 60-71. 
[41] H. Pan, R. Li, M. Gao, Y. Liu, Q. Wang, J. Alloys Compd. 404-406 (2005) 669674.

[42] K. Young, T. Ouchi, M.A. Fetcenko, J. Alloys Compd. 476 (2009) 774-781.

[43] X.B. Yu, Z. Wu, B.J. Xia, N.X. Xu, J. Chem. Phys. 121 (2004) 987-90.

[44] K. Young, 'Metal Hydrides', in Elsevier reference module in Chemistry, molecular sciences and chemical engineering, ed. J. Reedijk, Elsevier, Waltham, MA. doi: 10.1016/B978-0-12-409547-2.05894-7.

[45] K. Young, B. Chao, Y. Liu, J. Nei, J. Alloys Compd. 606 (2014) 97-104.

[46] F. Li, K. Young, T. Ouchi, M.A. Fetcenko, J. Alloys Compd. 471 (2009) 371-7.

[47] K. Young, K. Young, T. Ouchi, B. Huang, B. Chao, M.A. Fetcenko, L.A. Bendersky, K. Wang, C. Chiu, J. Alloys Compd. 506 (2010) 841-848.

[48] K. Young, M. Young, S. Chang, B. Huang, J. Alloys Compd. 560 (2013) 33-41.

[49] M. Young, S. Chang, K. Young, J. Nei, J. Alloys Compd. 580 (2013) S171-S174. 


\section{Figure Captions}

Fig. 1

XRD patterns using $\mathrm{Cu}-\mathrm{K}_{\alpha}$ as the radiation source for alloys P8 (a), P9 (b), P10 (c), P11

(d), P12 (e), P13 (f), and P14 (g). Vertical lines are used to indicate shifts in both C14 and BCC peaks to lower angles.

Fig. 2

Lattice constants $a$ and $c$ from $\mathrm{C} 14$ phase and $a$ from BCC phase as functions of Ticontent in the alloy design.

Fig. 3

SEM back-scattering electron images for alloys P8 (a), P9 (b), P10 (c), P11 (d), P12 (e), P13 (f), and P14 (g). Chemical compositions in the numbered areas measured by EDS are listed in Table 3.

Fig. 4

The major constituent elements and the metal ratio in C14 phase (a) and BCC phase (b) as functions of Ti-content in the alloy design.

Fig. 5 
Schematic of C14 unit cell. It is composed of alternating A2B and B3 layers stacked along the $c$ axis. Larger A-atoms occupy $4 f$-sites while smaller B-atoms occupy $2 a$-sites (on the A2B layer) and $6 h$-sites (on the B3 layer).

Fig. 6

PCT isotherms of alloys $\mathrm{P} 8 *, \mathrm{P} 8, \mathrm{P} 9, \mathrm{P} 10$ at $30^{\circ} \mathrm{C}$ (a) and $60^{\circ} \mathrm{C}$ (c), and $\mathrm{P} 11, \mathrm{P} 12, \mathrm{P} 13$, and $\mathrm{P} 14$ at $30^{\circ} \mathrm{C}$ (b) and $60^{\circ} \mathrm{C}(\mathrm{d})$. Open and solid symbols are for absorption and desorption curves, respectively. $\mathrm{P} 8$ * was measured at lower maximum pressure (1.1 MPa) while all other samples were measured up to $5 \mathrm{MPa}$.

\section{Fig. 7}

The half-cell discharge capacity measured at $4 \mathrm{~mA} \mathrm{~g}^{-1}$ (a) and high-rate dischargeability (HRD) (b) of the first 13 cycles.

Fig. 8

Hydrogen storage capacities converted from gaseous phase hydrogen storage and as measured electrochemically as functions of Ti-content.

Fig. 9

Plots of diffusion coefficient and C14-phase crystallite size as functions of Ti-content. The trends indicate that hydrogen diffuses easier within an alloy with smaller C14-phase crystallites. 
Table 1 Design compositions (in bold) and ICP results in at.\%.

\begin{tabular}{|c|c|c|c|c|c|c|c|c|c|c|c|}
\hline & & $\mathrm{Ti}$ & $\mathrm{Zr}$ & $\mathrm{V}$ & $\mathrm{Cr}$ & $\mathrm{Mn}$ & $\mathrm{Fe}$ & Co & $\mathrm{Ni}$ & $\mathrm{Al}$ & $\begin{array}{l}\mathrm{B} / \mathrm{A} \\
\text { ratio }\end{array}$ \\
\hline \multirow[t]{2}{*}{ P8 } & Design & 13.6 & 2.1 & 44.0 & 13.2 & 6.9 & 2.7 & 1.4 & 15.7 & 0.3 & 5.36 \\
\hline & $\mathrm{ICP}$ & 13.8 & 2.0 & 43.1 & 13.1 & 6.5 & 2.8 & 1.4 & 16.7 & 0.6 & 5.33 \\
\hline \multirow[t]{2}{*}{ P9 } & Design & 15.6 & 2.1 & 44.0 & 11.2 & 6.9 & 2.7 & 1.4 & 15.7 & 0.3 & 4.64 \\
\hline & $\mathrm{ICP}$ & 15.8 & 2.0 & 44.6 & 11.1 & 6.5 & 2.7 & 1.4 & 15.5 & 0.3 & 4.61 \\
\hline \multirow[t]{2}{*}{ P10 } & Design & 17.6 & 2.1 & 44.0 & 9.2 & 6.9 & 2.7 & 1.4 & 15.7 & 0.3 & 4.07 \\
\hline & $\mathrm{ICP}$ & 18.1 & 2.1 & 43.6 & 9.3 & 6.5 & 2.8 & 1.5 & 15.8 & 0.3 & 3.95 \\
\hline \multirow[t]{2}{*}{ P11 } & Design & 19.6 & 2.1 & 44.0 & 7.2 & 6.9 & 2.7 & 1.4 & 15.7 & 0.3 & 3.60 \\
\hline & ICP & 19.9 & 2.1 & 44.1 & 6.8 & 6.6 & 2.7 & 1.5 & 16.0 & 0.3 & 3.55 \\
\hline \multirow[t]{2}{*}{ P12 } & Design & 21.6 & 2.1 & 44.0 & 5.2 & 6.9 & 2.7 & 1.4 & 15.7 & 0.3 & 3.22 \\
\hline & $\mathrm{ICP}$ & 22.1 & 2.1 & 43.6 & 5.4 & 6.6 & 2.7 & 1.5 & 15.7 & 0.3 & 3.13 \\
\hline \multirow[t]{2}{*}{ P13 } & Design & 23.6 & 2.1 & 44.0 & 3.2 & 6.9 & 2.7 & 1.4 & 15.7 & 0.3 & 2.89 \\
\hline & ICP & 23.7 & 2.5 & 43.9 & 3.3 & 6.5 & 2.7 & 1.4 & 15.7 & 0.3 & 2.82 \\
\hline \multirow[t]{2}{*}{ P14 } & Design & 25.6 & 2.1 & 44.0 & 1.2 & 6.9 & 2.7 & 1.4 & 15.7 & 0.3 & 2.61 \\
\hline & ICP & 26.1 & 2.3 & 43.8 & 1.1 & 6.5 & 2.7 & 1.3 & 15.8 & 0.3 & 2.52 \\
\hline
\end{tabular}


Table 2 Lattice constants, unit cell volumes, phase abundances, and crystallite sizes of C14 and BCC phases of alloys P8 to P14 from XRD analysis. FWHM and XS denote full-width at half maximum and crystallite size, respectively.

\begin{tabular}{lccccccccccc}
\hline & & & \multicolumn{3}{c}{ C14 phase } & \multicolumn{3}{c}{ BCC phase } \\
& $a(\AA)$ & $c(\AA)$ & $c l a$ & $\begin{array}{c}\text { Unit cell vol. } \\
\left(\AA^{3}\right)\end{array}$ & $\begin{array}{c}\text { FWHM } \\
(103)\end{array}$ & XS $(\AA)$ & $\begin{array}{c}\text { Abundance } \\
(\%)\end{array}$ & $a(\AA)$ & FWHM $(200)$ & XS $(\AA)$ & $\begin{array}{c}\text { Abundance } \\
(\%)\end{array}$ \\
\hline P8 & 4.9024 & 7.9728 & 1.626 & 165.94 & 0.504 & 185 & 11.0 & 2.9683 & 0.646 & 155 \\
P9 & 4.9179 & 8.0045 & 1.628 & 167.65 & 0.408 & 237 & 20.8 & 2.9751 & 0.667 & 149 \\
P10 & 4.9280 & 8.0316 & 1.630 & 168.91 & 0.427 & 225 & 22.2 & 2.9835 & 0.688 & 144 & 79.2 \\
P11 & 4.9339 & 8.0385 & 1.629 & 169.46 & 0.446 & 213 & 25.9 & 2.9888 & 0.685 & 144 & 74.8 \\
P12 & 4.9487 & 8.0682 & 1.630 & 171.11 & 0.498 & 188 & 35.9 & 3.0034 & 0.724 & 136 \\
P13 & 4.9542 & 8.0660 & 1.628 & 171.44 & 0.465 & 175 & 56.4 & 3.0100 & 0.774 & 126 \\
P14 & 4.9592 & 8.0666 & 1.627 & 171.80 & 0.482 & 163 & 52.5 & 3.0165 & 0.814 & 120 \\
\hline
\end{tabular}


Table 3 Summary of EDS results. All compositions are in at.\%. Compositions of C14 and BCC phase are in italic and bold, respectively.

\begin{tabular}{|c|c|c|c|c|c|c|c|c|c|c|c|}
\hline & $\mathrm{Zr}$ & $\mathrm{Ti}$ & $\mathrm{V}$ & $\mathrm{Cr}$ & $\mathrm{Mn}$ & $\mathrm{Fe}$ & Co & $\mathrm{Ni}$ & $\mathrm{Al}$ & $\mathrm{B} / \mathrm{A}$ & Phase \\
\hline Fig. 3a-1 & 8.8 & 23.3 & 18.8 & 2.6 & 7.7 & 3.7 & 1.9 & 32.3 & 1.0 & 2.12 & $\mathrm{AB}_{2}$ \\
\hline 2 & 2.6 & 35.0 & 9.8 & 1.7 & 3.9 & 2.9 & 3.3 & 39.6 & 1.2 & 1.66 & TiNi \\
\hline 3 & 8.2 & 35.1 & 16.1 & 1.4 & 4.5 & 2.0 & 1.4 & 30.8 & 0.5 & 1.31 & $\mathrm{TiNi} / \mathrm{BCC}$ \\
\hline 4 & 0.1 & 6.1 & 58.6 & 19.2 & 6.7 & 2.7 & 0.8 & 5.4 & 0.4 & 15.13 & BCC \\
\hline 5 & 93.1 & 1.6 & 2.8 & 1.0 & 0.3 & 0.2 & 0.1 & 0.9 & 0.1 & 0.06 & $\mathrm{Zr}$ \\
\hline Fig. 3b- 1 & 8.5 & 25.4 & 20.8 & 2.9 & 6.3 & 2.5 & 1.6 & 31.3 & 0.7 & 1.95 & $\mathrm{AB}_{2}$ \\
\hline 2 & 3.3 & 36.8 & 9.5 & 1.2 & 3.0 & 1.8 & 2.4 & 41.3 & 0.8 & 1.50 & TiNi \\
\hline 3 & 5.1 & 39.8 & 14.8 & 2.3 & 4.2 & 2.7 & 2.1 & 28.6 & 0.3 & 1.22 & $\mathrm{TiNi} / \mathrm{BCC}$ \\
\hline 4 & 0.1 & 7.1 & 60.8 & 16.4 & 7.0 & 2.6 & 0.8 & 4.9 & 0.3 & 12.89 & BCC \\
\hline 5 & 50.0 & 24.8 & 8.7 & 1.2 & 1.7 & 1.2 & 1.0 & 11.2 & 0.2 & 0.34 & $\mathrm{Zr}$ \\
\hline Fig. $3 c-1$ & 7.7 & 28.5 & 20.2 & 2.3 & 6.6 & 2.9 & 1.8 & 29.3 & 0.6 & 1.76 & $\mathrm{AB}_{2}$ \\
\hline 2 & 2.5 & 38.9 & 9.2 & 1.4 & 3.5 & 3.2 & 3.4 & 37.2 & 0.6 & 1.41 & TiNi \\
\hline 3 & 0.1 & 7.8 & 63.7 & 14.6 & 6.0 & 2.3 & 0.8 & 4.5 & 0.3 & 11.67 & BCC \\
\hline 4 & 36.1 & 18.2 & 21.3 & 3.4 & 2.9 & 1.8 & 1.4 & 14.5 & 0.4 & 0.84 & $\mathrm{Zr}$ \\
\hline Fig. 3d- 1 & 6.4 & 30.9 & 21.6 & 2.0 & 7.2 & 3.2 & 1.9 & 26.4 & 0.6 & 1.69 & $\mathrm{AB}_{2}$ \\
\hline 2 & 2.5 & 40.7 & 8.0 & 0.8 & 3.6 & 3.5 & 3.5 & 36.9 & 0.4 & 1.31 & TiNi \\
\hline 3 & 0.1 & 9.3 & 65.1 & 10.9 & 6.7 & 2.3 & 0.9 & 4.5 & 0.3 & 9.65 & BCC \\
\hline Fig. 3e- 1 & 5.8 & 32.5 & 22.8 & 1.2 & 5.4 & 2.3 & 1.6 & 27.8 & 0.6 & 1.61 & $\mathrm{AB}_{2}$ \\
\hline 2 & 2.3 & 41.6 & 8.3 & 0.5 & 3.3 & 3.3 & 3.5 & 36.7 & 0.5 & 1.28 & TiNi \\
\hline 3 & 0.1 & 11.0 & 65.4 & 8.0 & 7.2 & 2.5 & 0.7 & 4.7 & 0.4 & 8.01 & BCC \\
\hline Fig. 3f- 1 & 4.7 & 34.5 & 21.5 & 1.1 & 7.1 & 2.7 & 1.5 & 26.4 & 0.5 & 1.55 & $\mathrm{AB}_{2}$ \\
\hline 2 & 2.1 & 42.3 & 10.0 & 0.5 & 3.7 & 2.5 & 2.4 & 36.2 & 0.3 & 1.25 & TiNi \\
\hline 3 & 2.9 & 48.1 & 12.3 & 0.4 & 4.0 & 2.3 & 1.9 & 27.7 & 0.4 & 0.96 & TiNi/BCC \\
\hline 4 & 0.1 & 13.5 & 64.9 & 5.5 & 7.1 & 3.0 & 0.8 & 4.8 & 0.2 & 6.35 & BCC \\
\hline Fig. $3 g-1$ & 2.9 & 37.9 & 19.0 & 0.4 & 5.3 & 2.9 & 2.3 & 28.9 & 0.5 & 1.45 & $\mathrm{AB}_{2}$ \\
\hline 2 & 1.9 & 42.2 & 9.8 & 0.1 & 4.3 & 3.5 & 3.1 & 34.6 & 0.5 & 1.27 & TiNi \\
\hline 3 & 3.3 & 47.7 & 13.2 & 0.2 & 4.6 & 2.6 & 2.1 & 26.1 & 0.2 & 0.96 & $\mathrm{TiNi} / \mathrm{BCC}$ \\
\hline 4 & 0.1 & 14.8 & 65.2 & 1.9 & 9.2 & 2.8 & 0.8 & 4.8 & 0.3 & 5.70 & BCC \\
\hline
\end{tabular}


Table 4 Summary of gaseous phase hydrogen storage properties and thermodynamic properties. Desorption pressure, hysteresis, and thermodynamic properties are calculated at $1.3 \mathrm{wt} . \%$ for P8-P10 and $1.5 \mathrm{wt} . \%$ for P11-P14.

\begin{tabular}{|c|c|c|c|c|c|c|c|c|}
\hline & $\begin{array}{c}\text { Des. pressure } \\
\text { @ } 30^{\circ} \mathrm{C} \\
(\mathrm{MPa})\end{array}$ & $\begin{array}{c}\text { Des. pressure } \\
\text { @ } 60^{\circ} \mathrm{C} \\
(\mathrm{MPa})\end{array}$ & $\begin{array}{c}\text { PCT hysteresis } \\
\text { @ } 30^{\circ} \mathrm{C}\end{array}$ & $\begin{array}{c}\text { PCT hysteresis } \\
\text { @ } 60^{\circ} \mathrm{C}\end{array}$ & $\begin{array}{l}\text { Max. cap. } \\
\text { @ 30 } \\
\text { (wt. } \%)\end{array}$ & $\begin{array}{l}\text { Rev. cap. } \\
\text { @ 30 } \\
\text { (wt. } \%)\end{array}$ & $\begin{array}{c}-\Delta H \\
\left(\mathrm{~kJ} \mathrm{~mol}^{-1}\right)\end{array}$ & $\begin{array}{c}-\Delta S \\
\left(\mathrm{~J} \mathrm{~mol}^{-1} \mathrm{~K}^{-1}\right)\end{array}$ \\
\hline P8* & NA & NA & NA & NA & 1.08 & 0.61 & 44.6 & 131 \\
\hline P9 & 0.20 & 0.70 & 1.09 & 0.95 & 1.69 & 1.23 & 35.4 & 123 \\
\hline P10 & 0.14 & 0.44 & 0.98 & 0.94 & 1.72 & 1.01 & 32.6 & 110 \\
\hline P11 & 0.097 & 0.32 & 0.97 & 2.01 & 1.81 & 0.88 & 33.3 & 110 \\
\hline P13 & 0.059 & 0.21 & 0.52 & 0.47 & 1.86 & 0.84 & 36.2 & 115 \\
\hline P14 & 0.035 & 0.16 & 0.24 & 0.14 & 1.92 & 0.80 & 41.8 & 129 \\
\hline
\end{tabular}


Table 5 Summary of electrochemical properties

\begin{tabular}{lccccccc}
\hline & $\begin{array}{c}4^{\text {th }} \text { cycle cap } \\
@ ~ 50 ~ \mathrm{~mA} \mathrm{~g}^{-1} \\
\left(\mathrm{mAh} \mathrm{g}^{-1}\right)\end{array}$ & $\begin{array}{c}4^{\text {th }} \text { cycle cap } \\
\text { @ 4 mA g } \\
\left(\mathrm{mAh} \mathrm{g}^{-1}\right)\end{array}$ & $\begin{array}{c}4^{\text {th }} \text { cycle } \\
\mathrm{HRD}\end{array}$ & $\begin{array}{c}\text { Activation cycle } \\
\text { to reach max. cap. }\end{array}$ & $\begin{array}{c}\text { Diffusion coefficient } \\
@ \text { RT } \\
\left(10^{-10} \mathrm{~cm}^{2} \mathrm{~s}^{-1}\right)\end{array}$ & $\begin{array}{c}\text { Exchange current } \\
@ \text { RT } \\
\left(\mathrm{mA} \mathrm{g}^{-1}\right)\end{array}$ & $\begin{array}{c}\text { Open circuit } \\
\text { voltage } \\
(\mathrm{V})\end{array}$ \\
\hline P8* & 166.7 & 172.0 & 0.989 & 2 & 1.54 & 33 & 1.354 \\
P8 & 346.5 & 368.2 & 0.941 & 4 & 1.38 & 31 & 1.289 \\
P9 & 364.3 & 420.3 & 0.867 & 5 & 1.33 & 30 & 1.277 \\
P10 & 321.0 & 434.1 & 0.726 & 5 & 1.32 & 23 & 1.276 \\
P11 & 298.1 & 426.0 & 0.700 & 3 & 1.28 & 26 & 1.274 \\
P12 & 258.8 & 463.1 & 0.580 & 2 & 1.57 & 17 & 1.262 \\
P13 & 268.8 & 448.2 & 0.600 & 2 & 1.81 & 11 & 1.251 \\
P14 & 230.5 & 398.2 & 0.578 & 1 & 1.62 & 15 & 1.257 \\
\hline
\end{tabular}




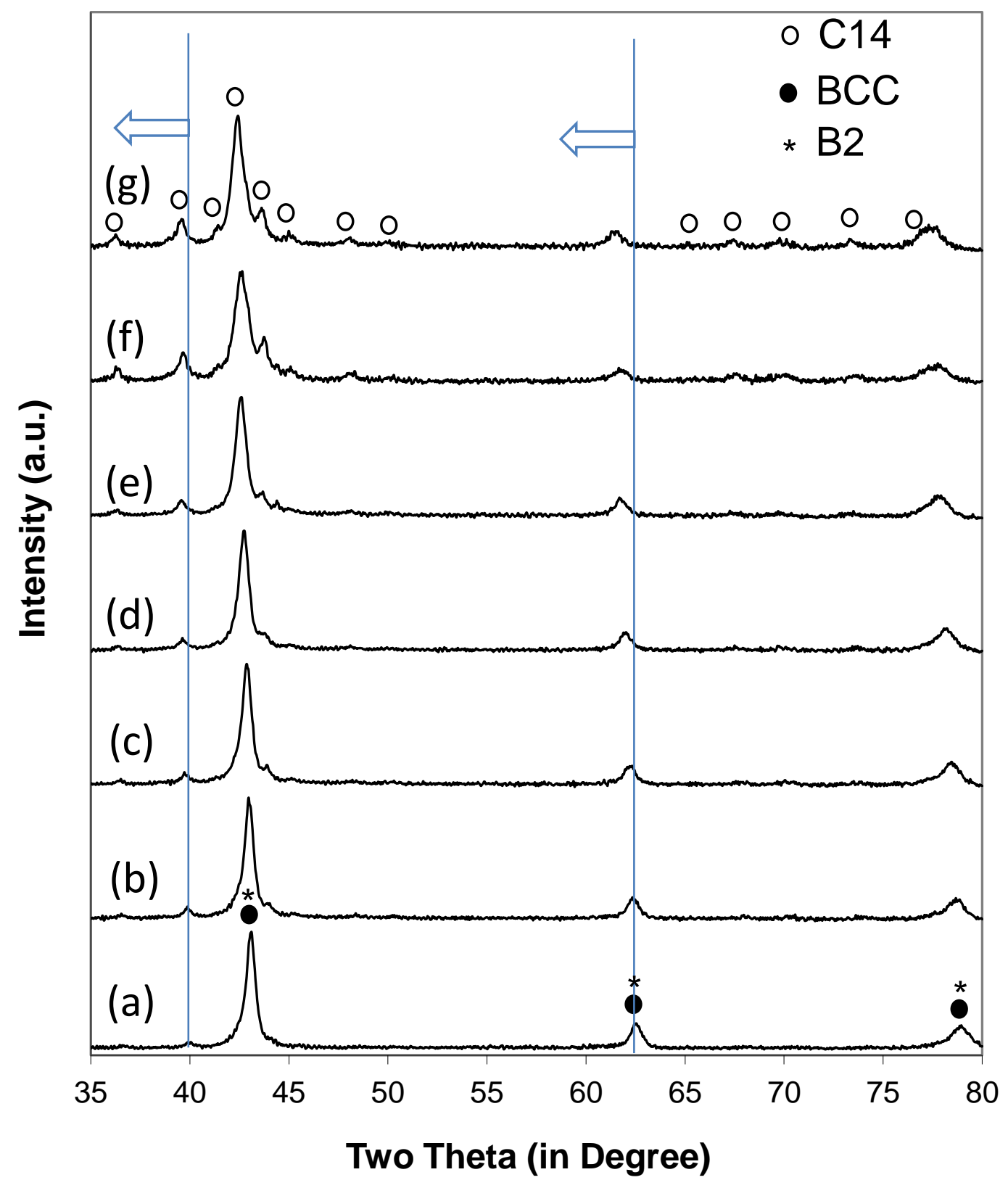

Fig. 1 


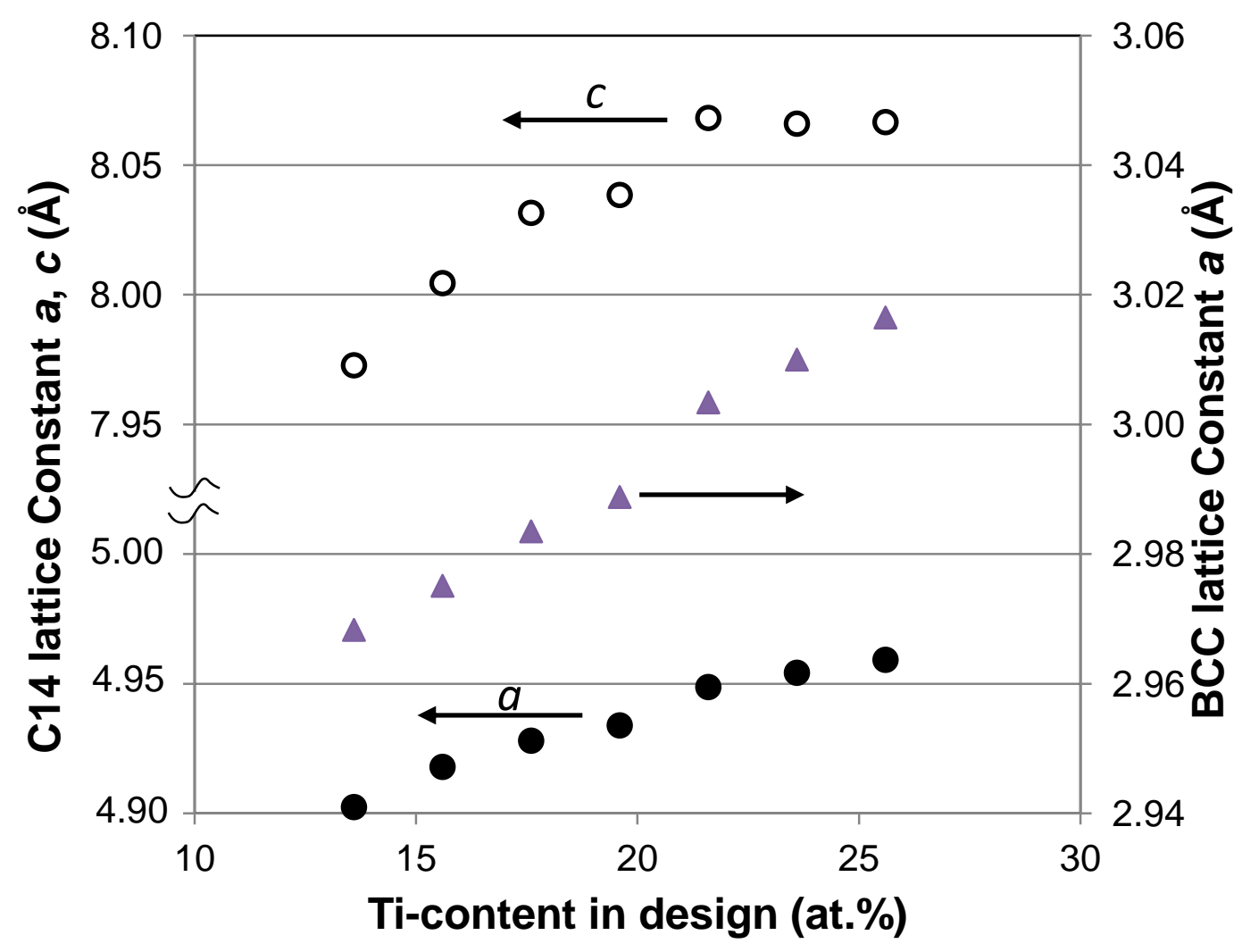

Fig. 2 


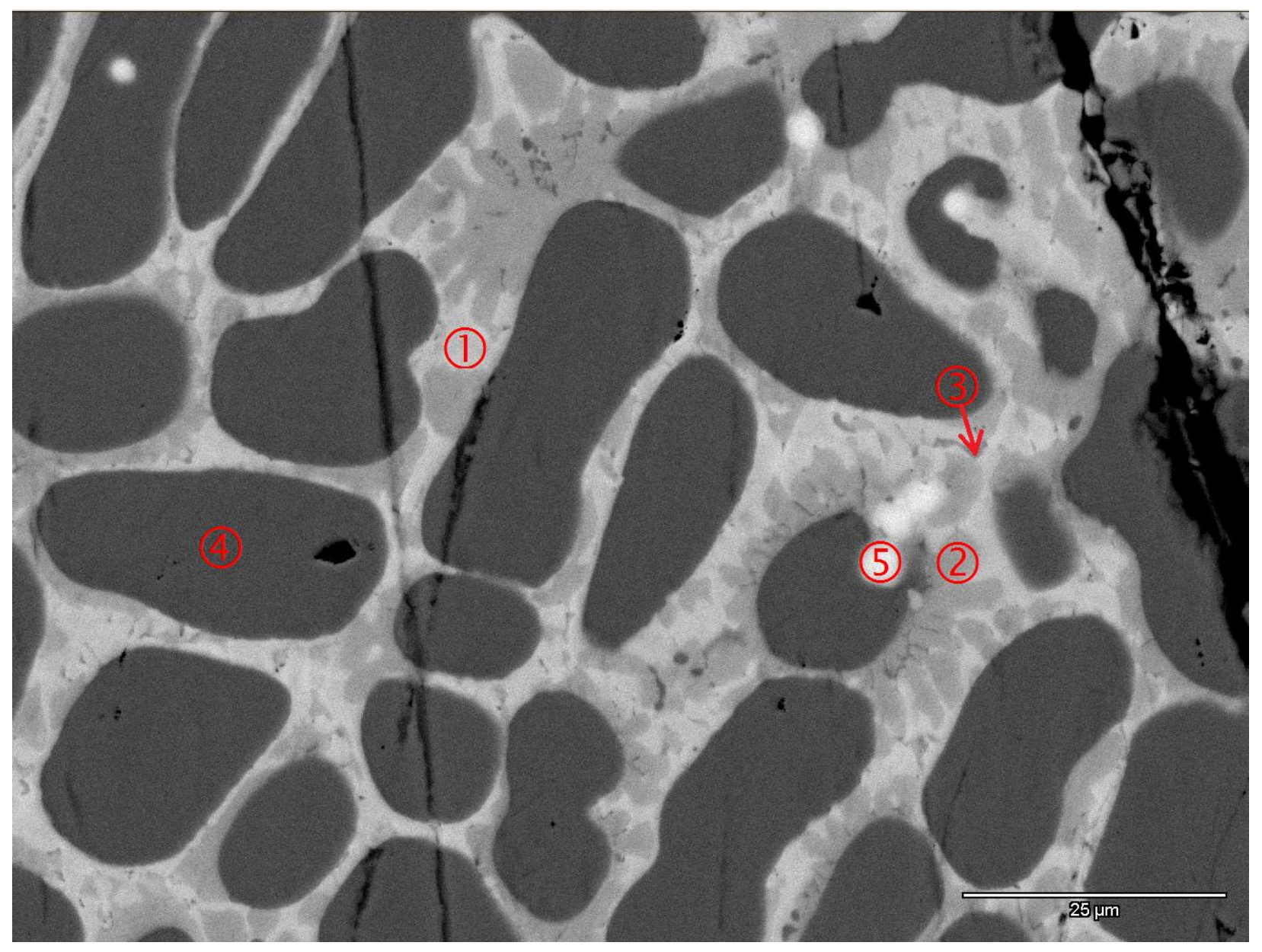

Fig. 3a 


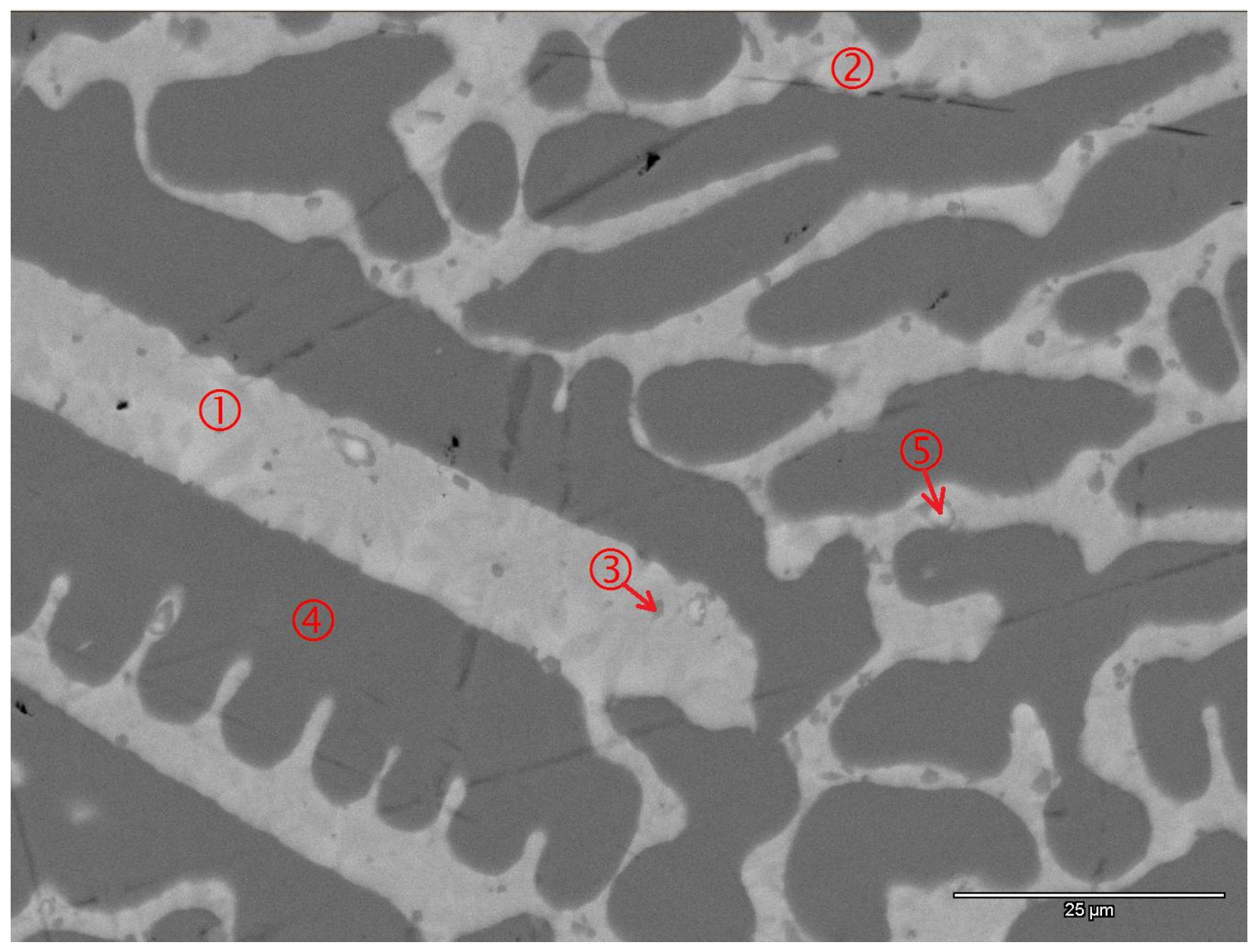

Fig. 3b 


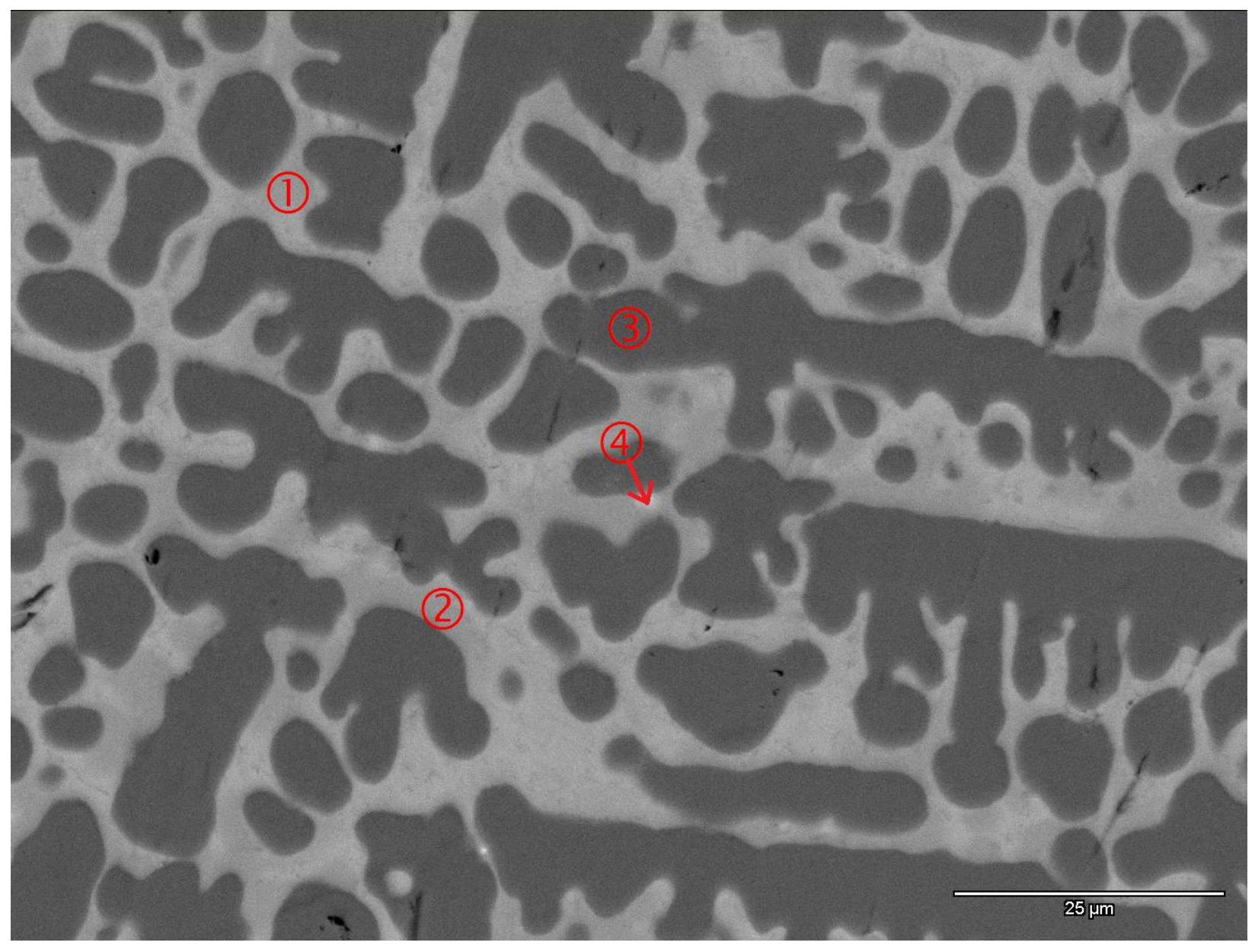

Fig. 3c 


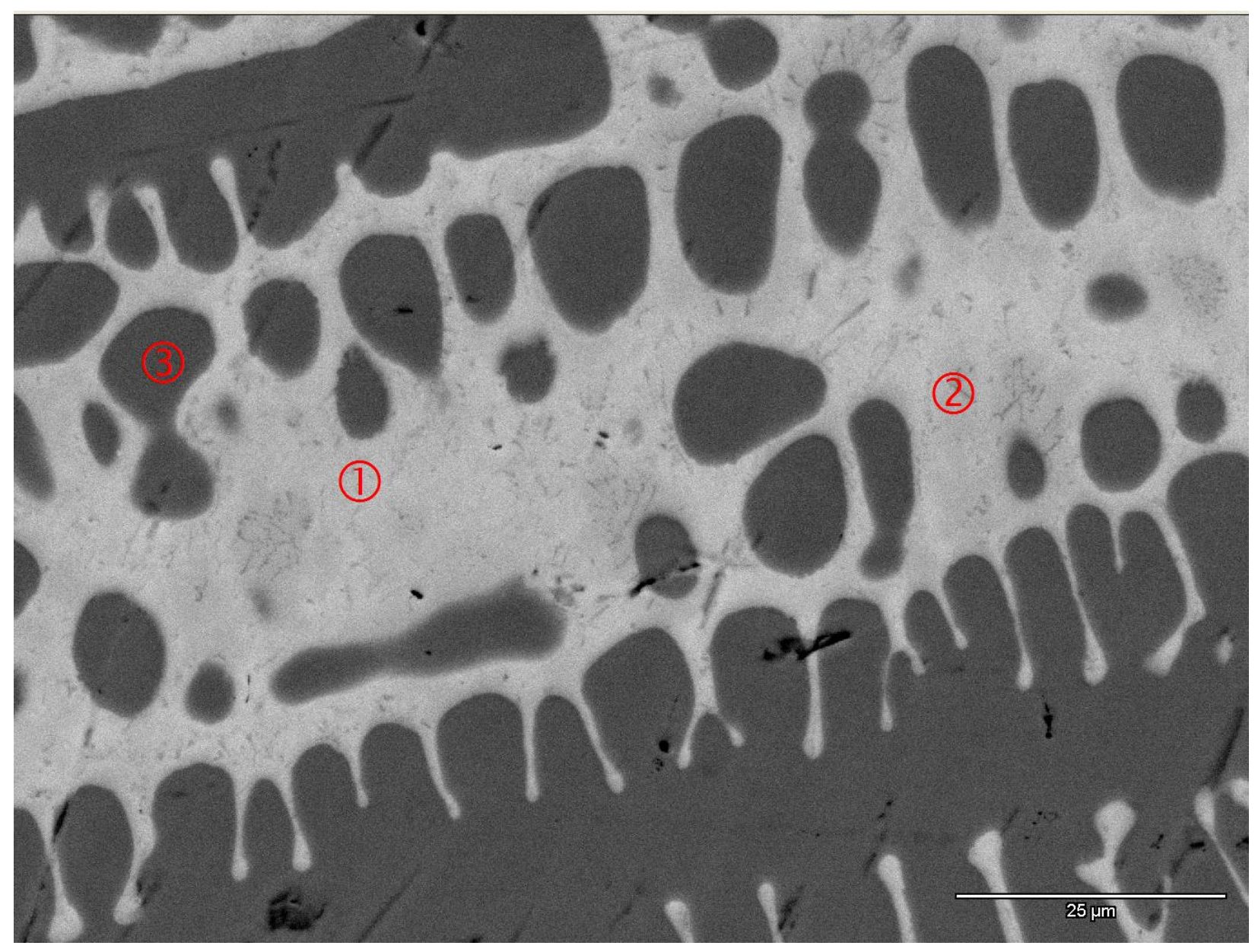

Fig. 3d 


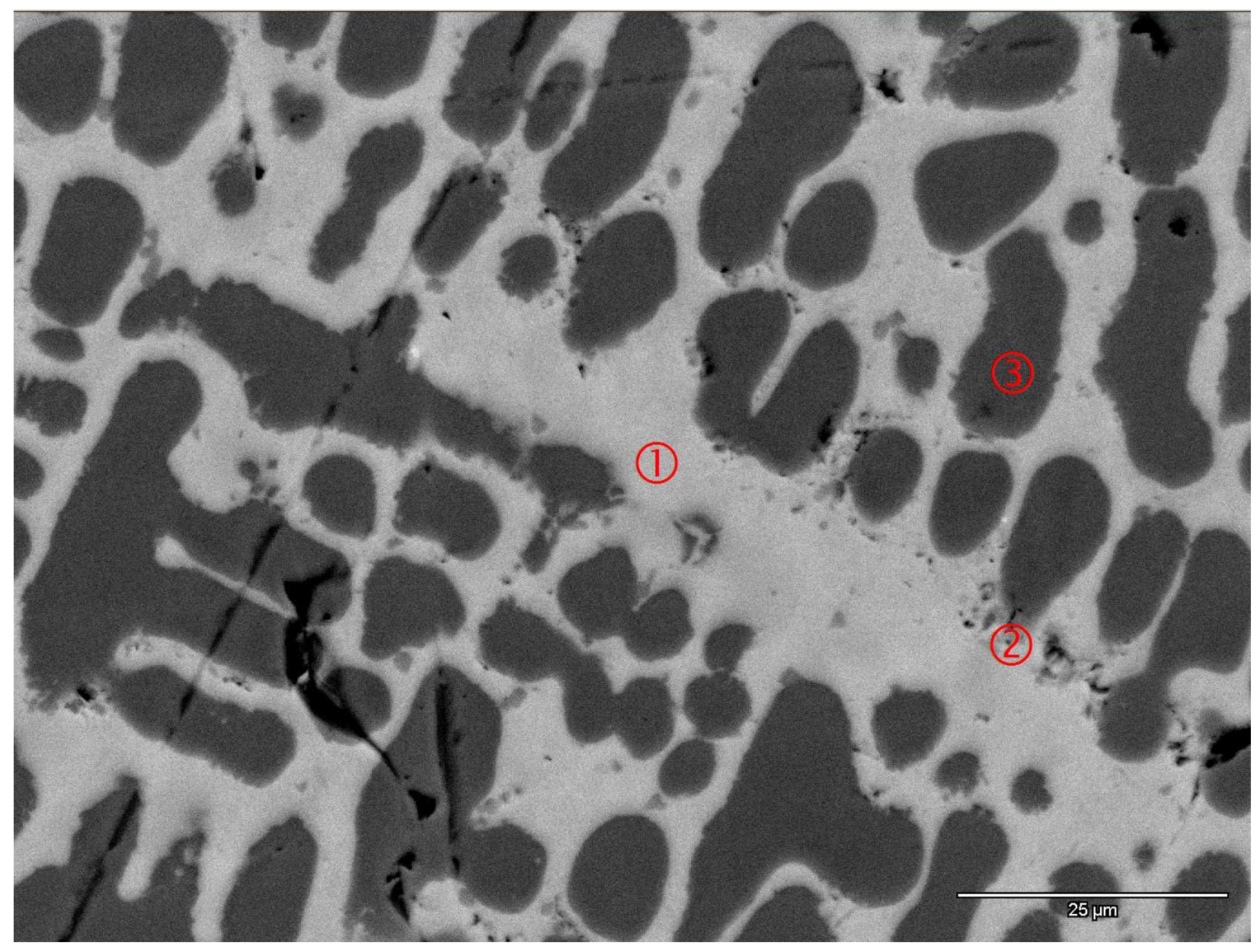

Fig. 3e 


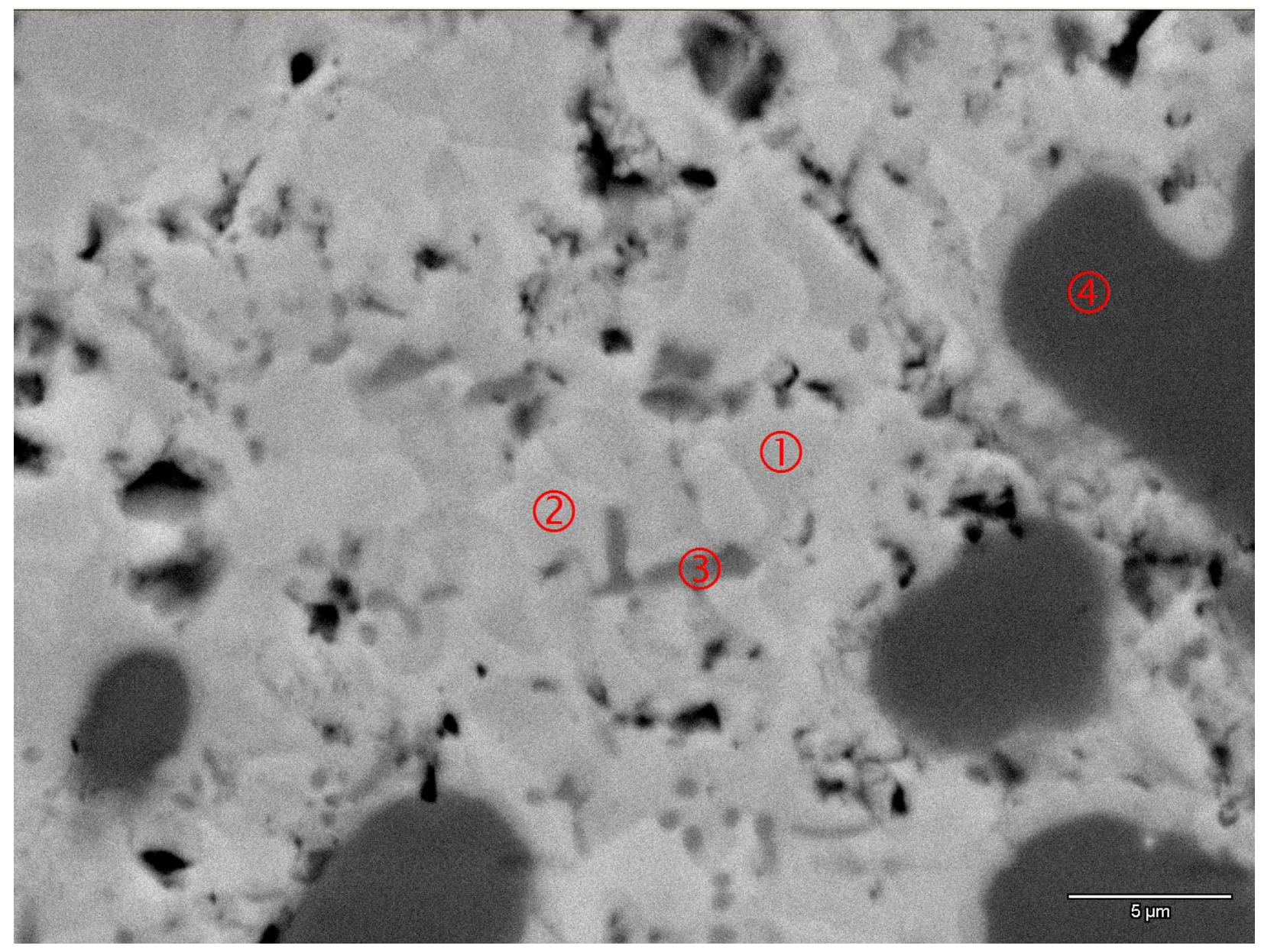

Fig. $3 f$ 


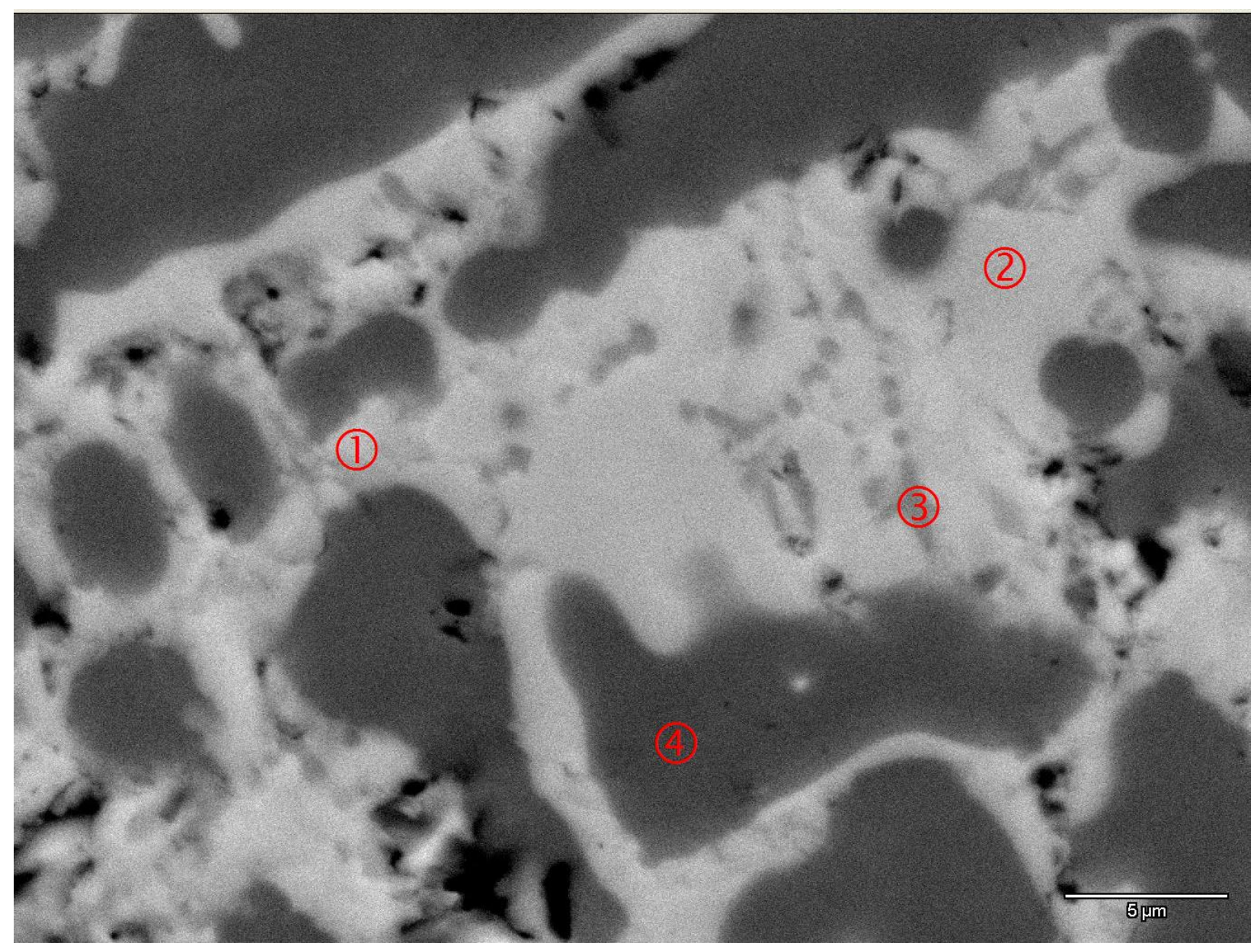

Fig. $3 g$ 


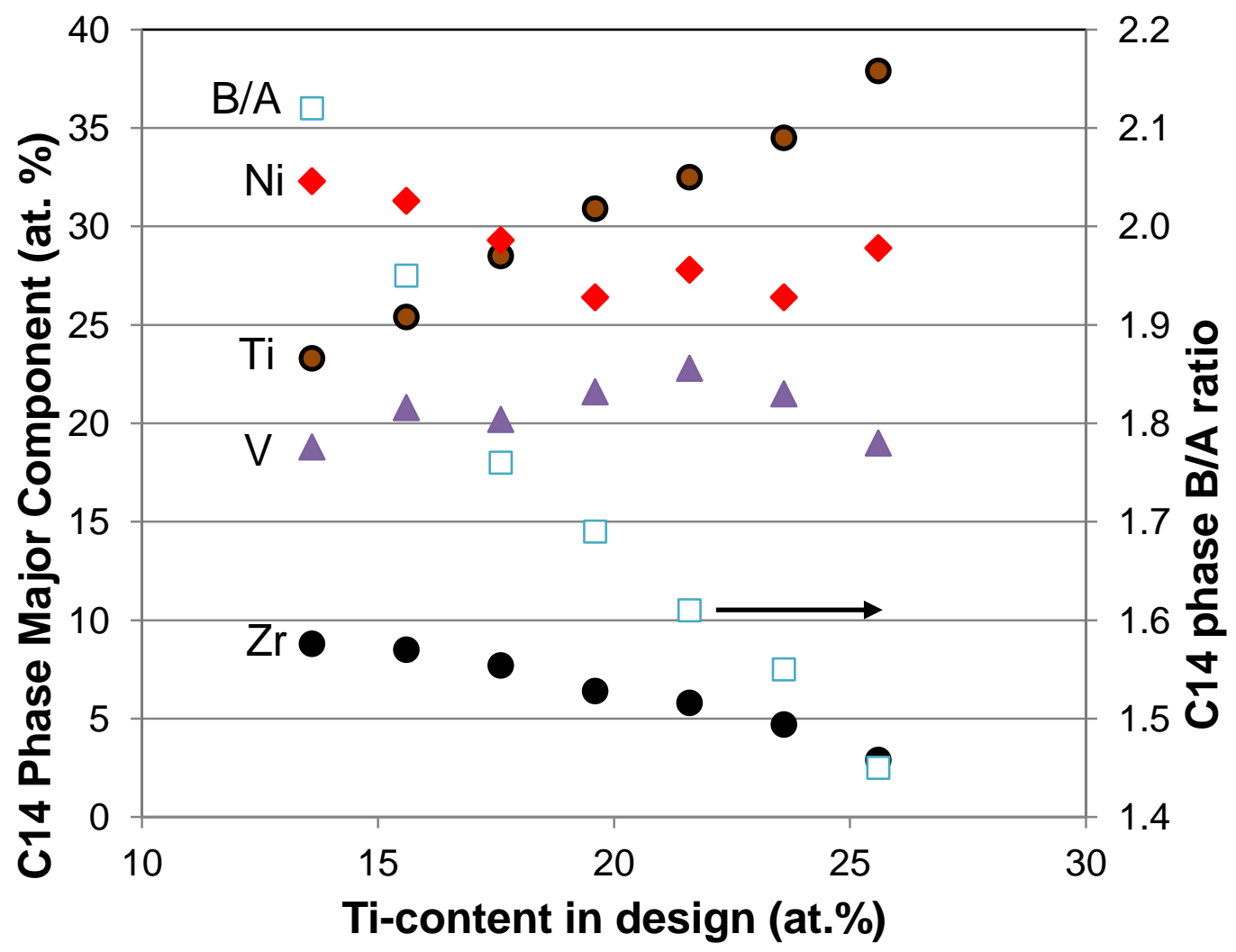

Fig. $4 a$ 


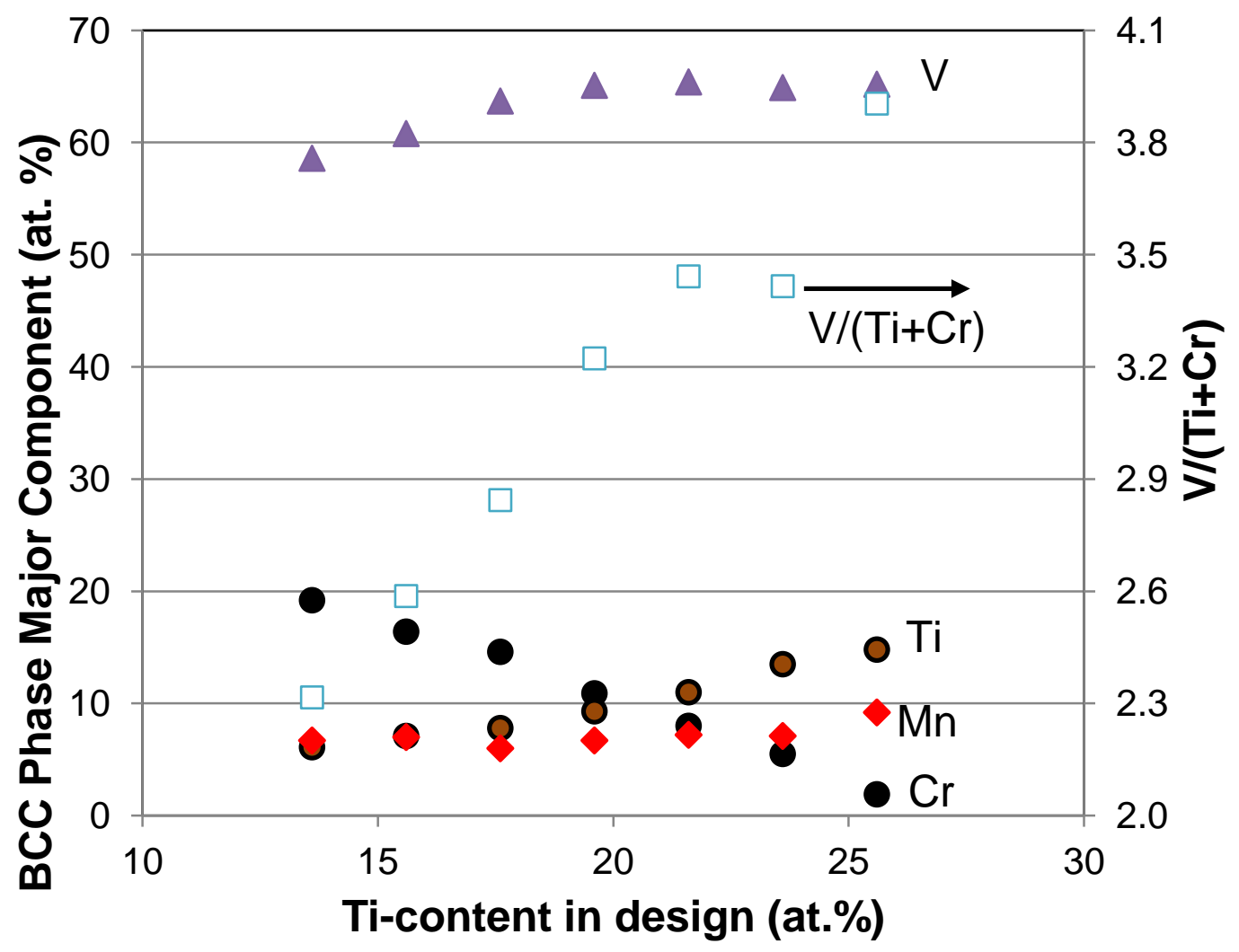

Fig. 4b 


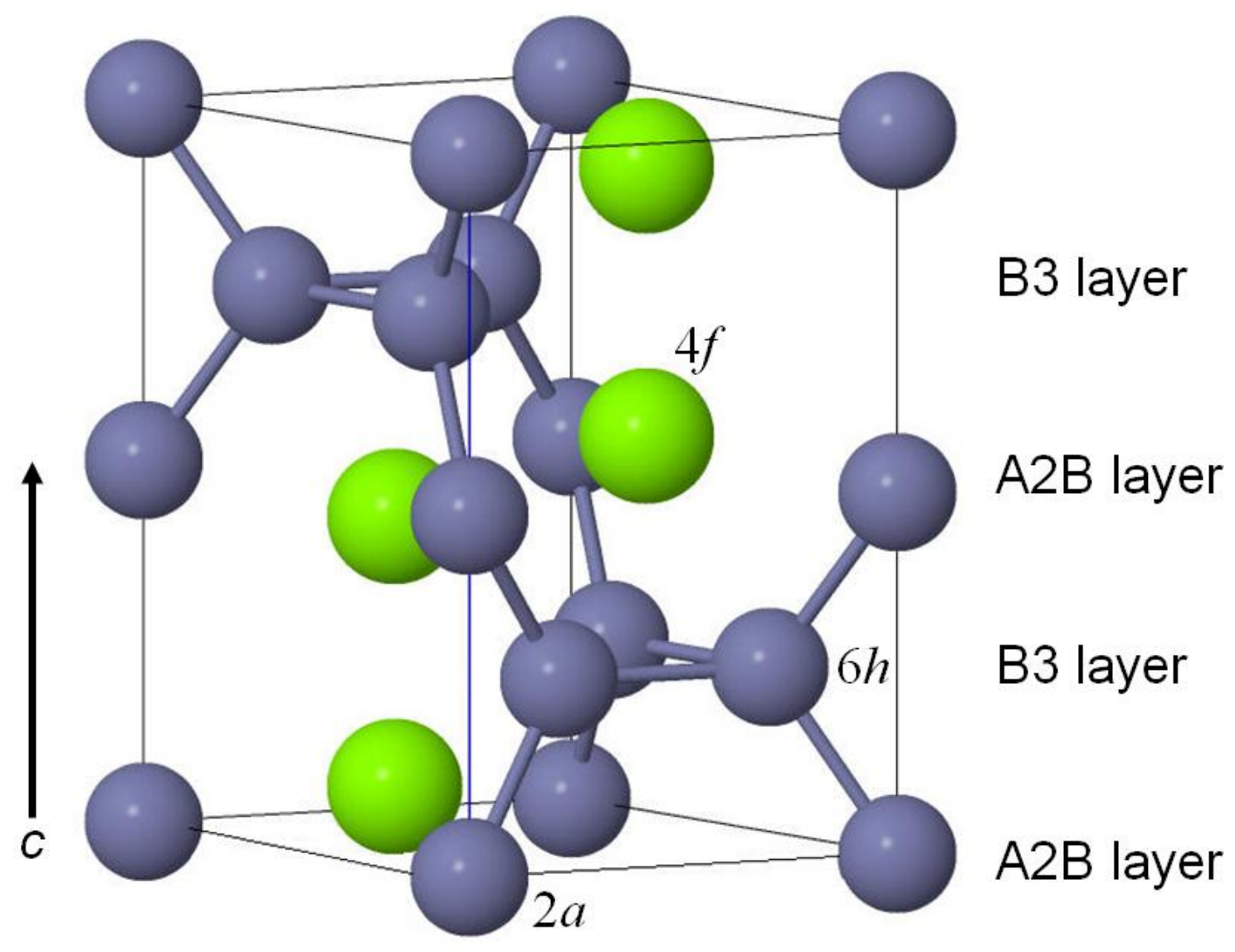

Fig. 5 


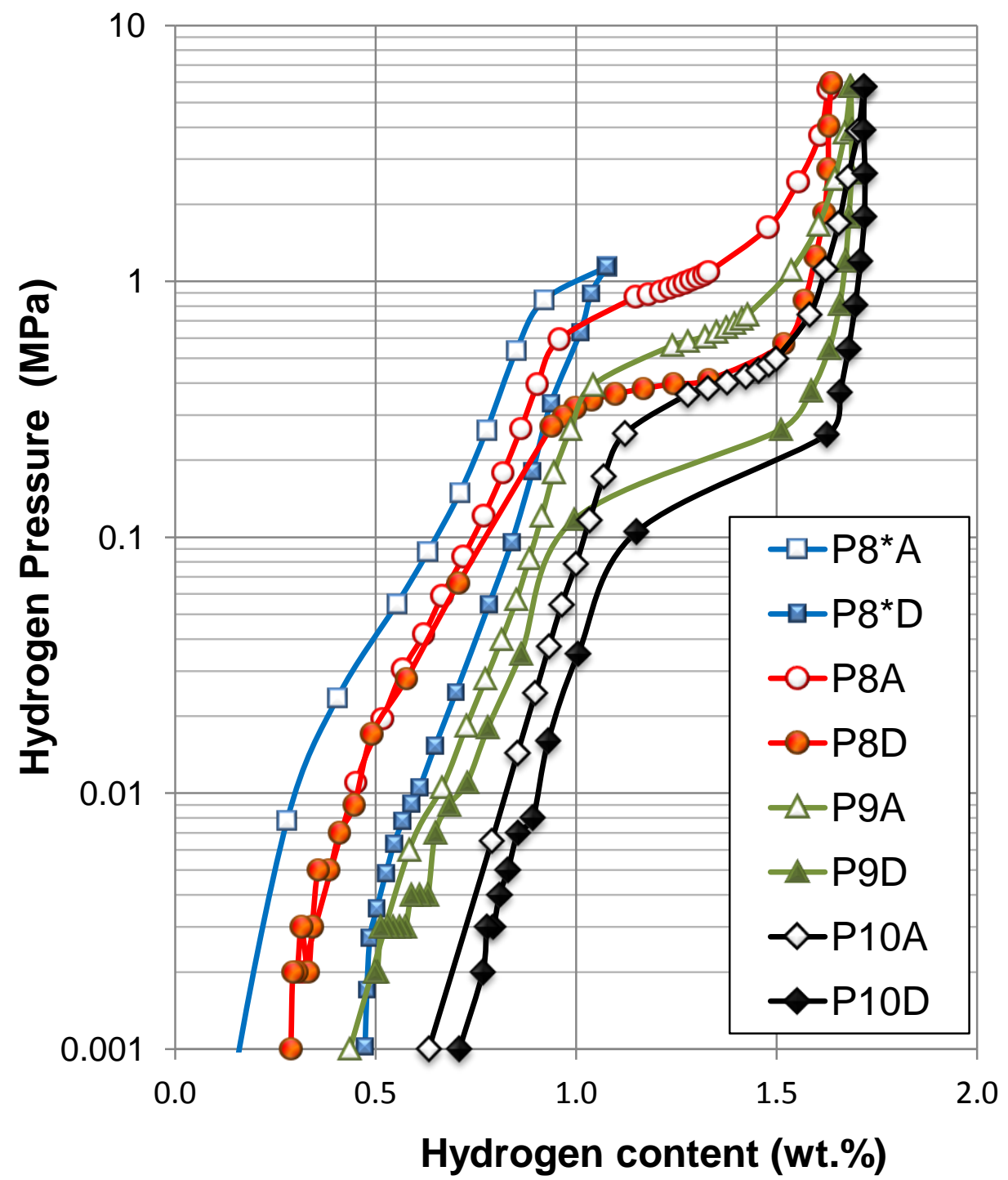

Fig. 6a 


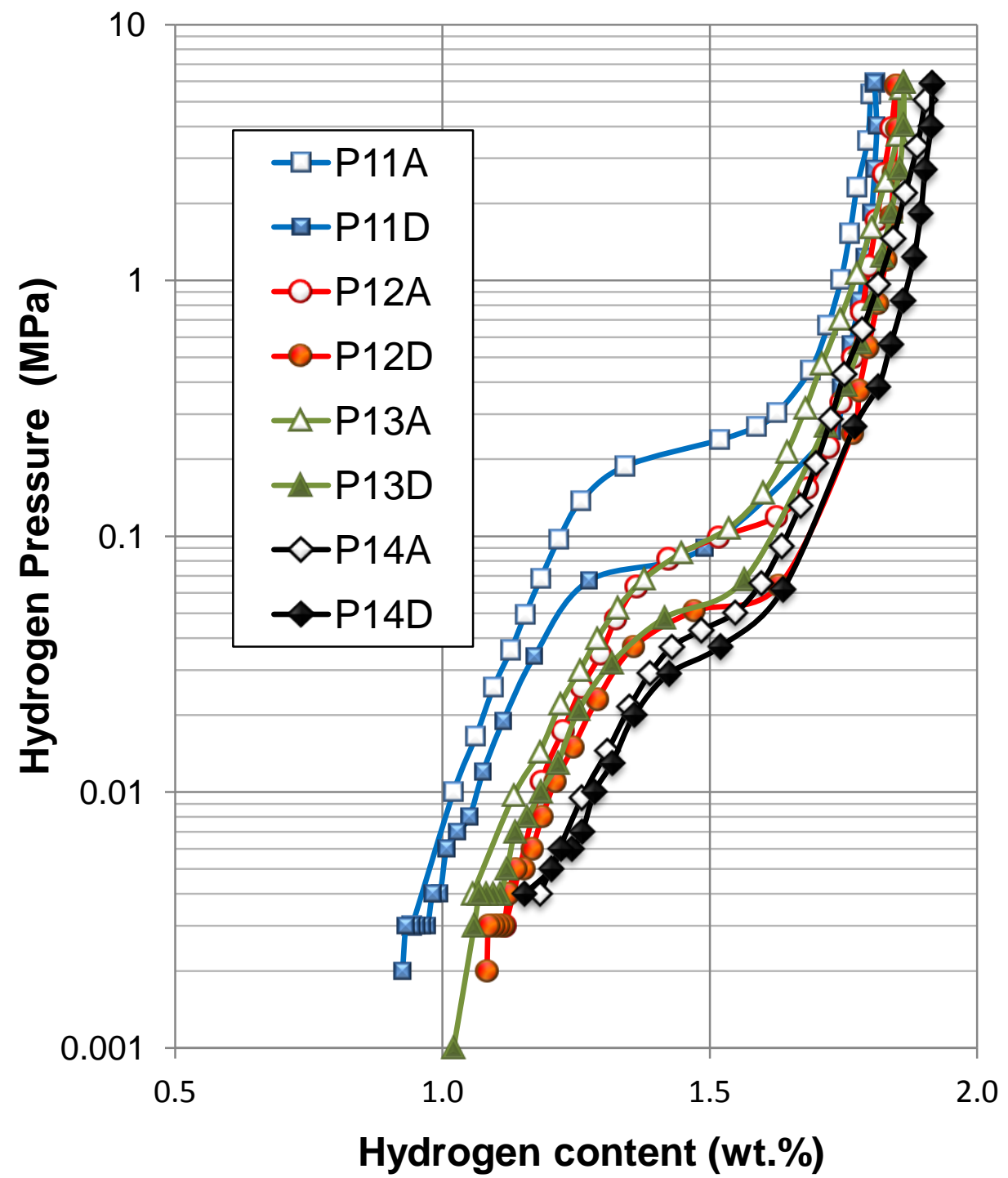

Fig. $6 b$ 


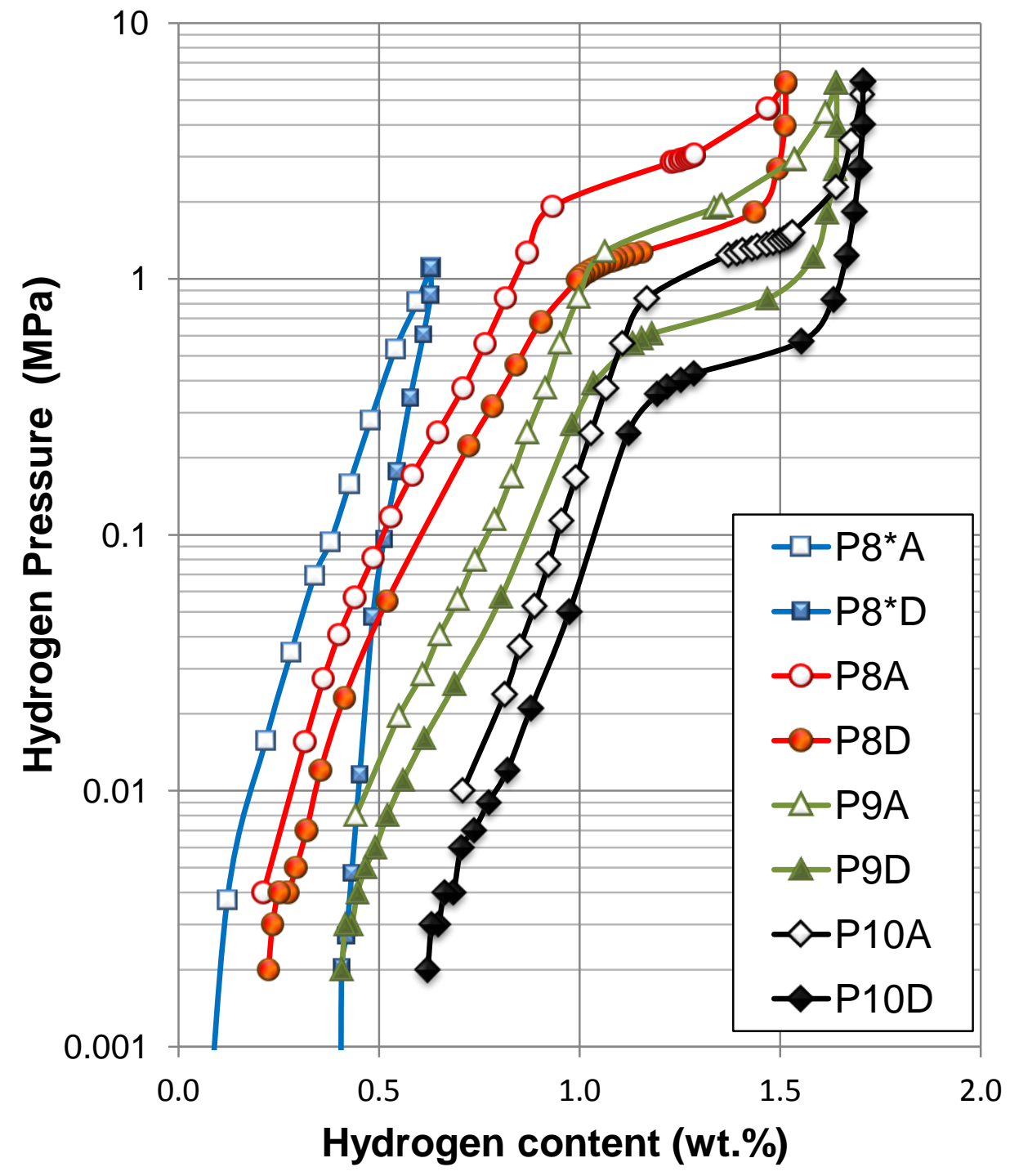

Fig. 6c 


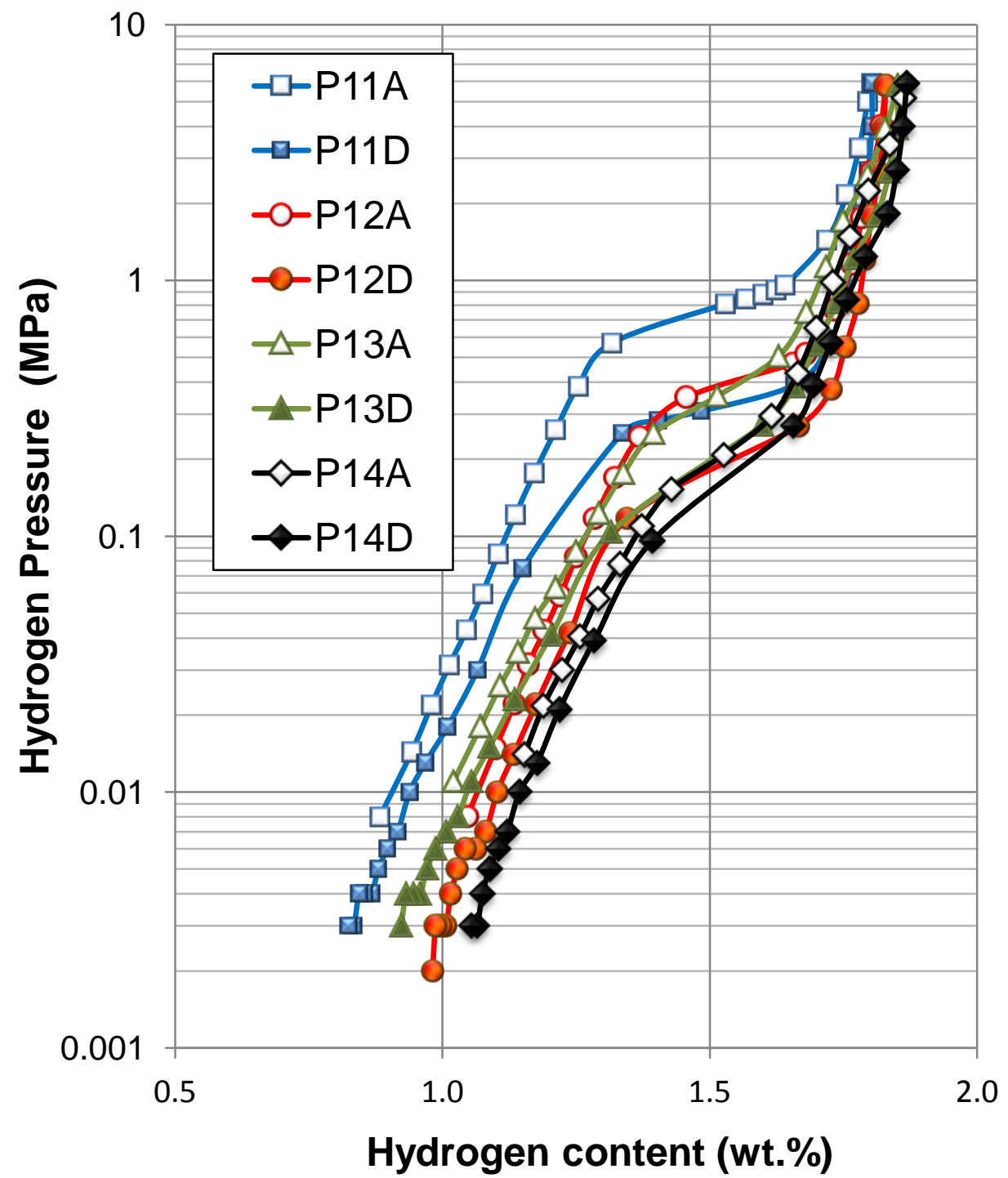

Fig. 6d 


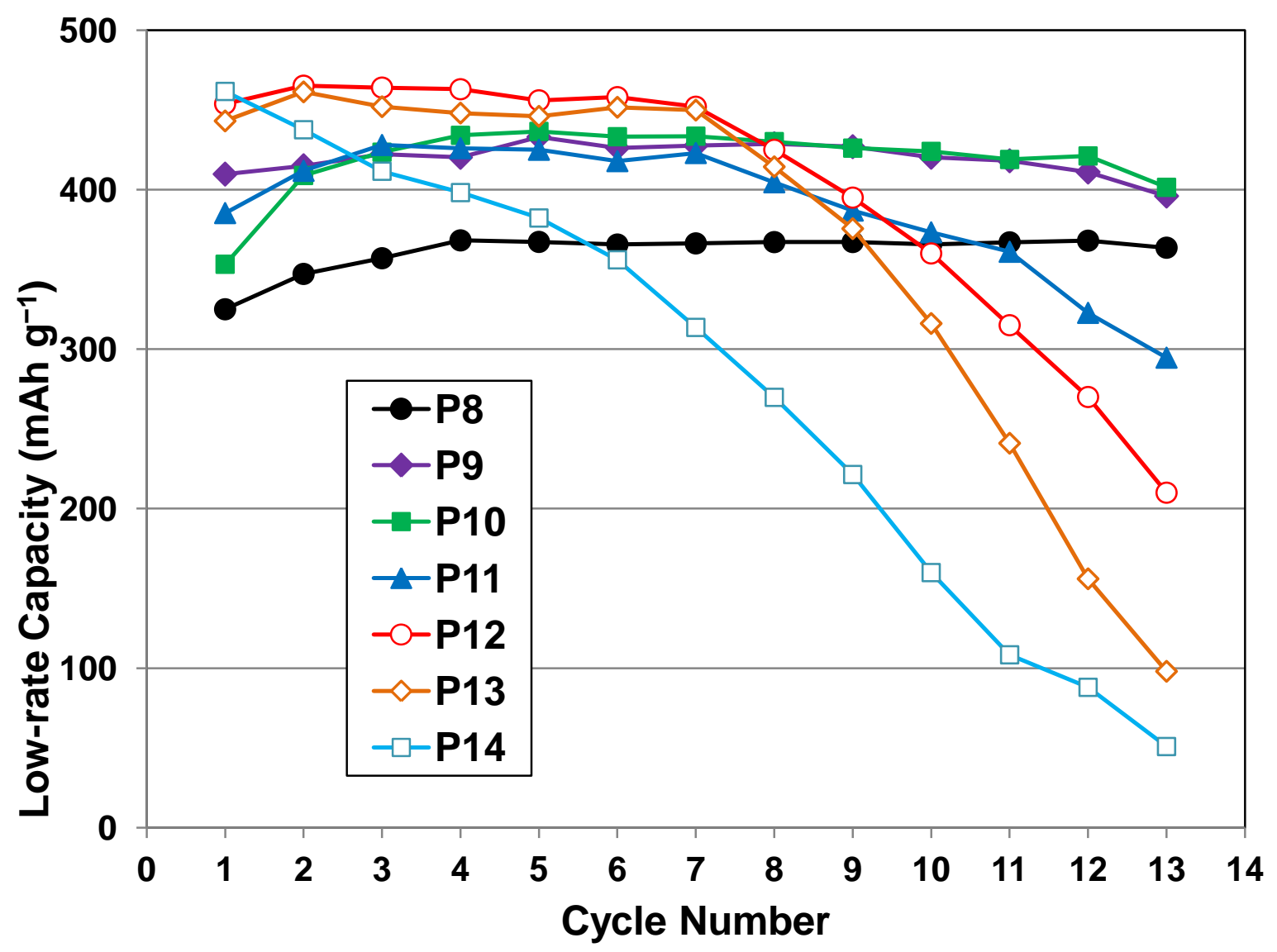

Fig. $7 a$ 


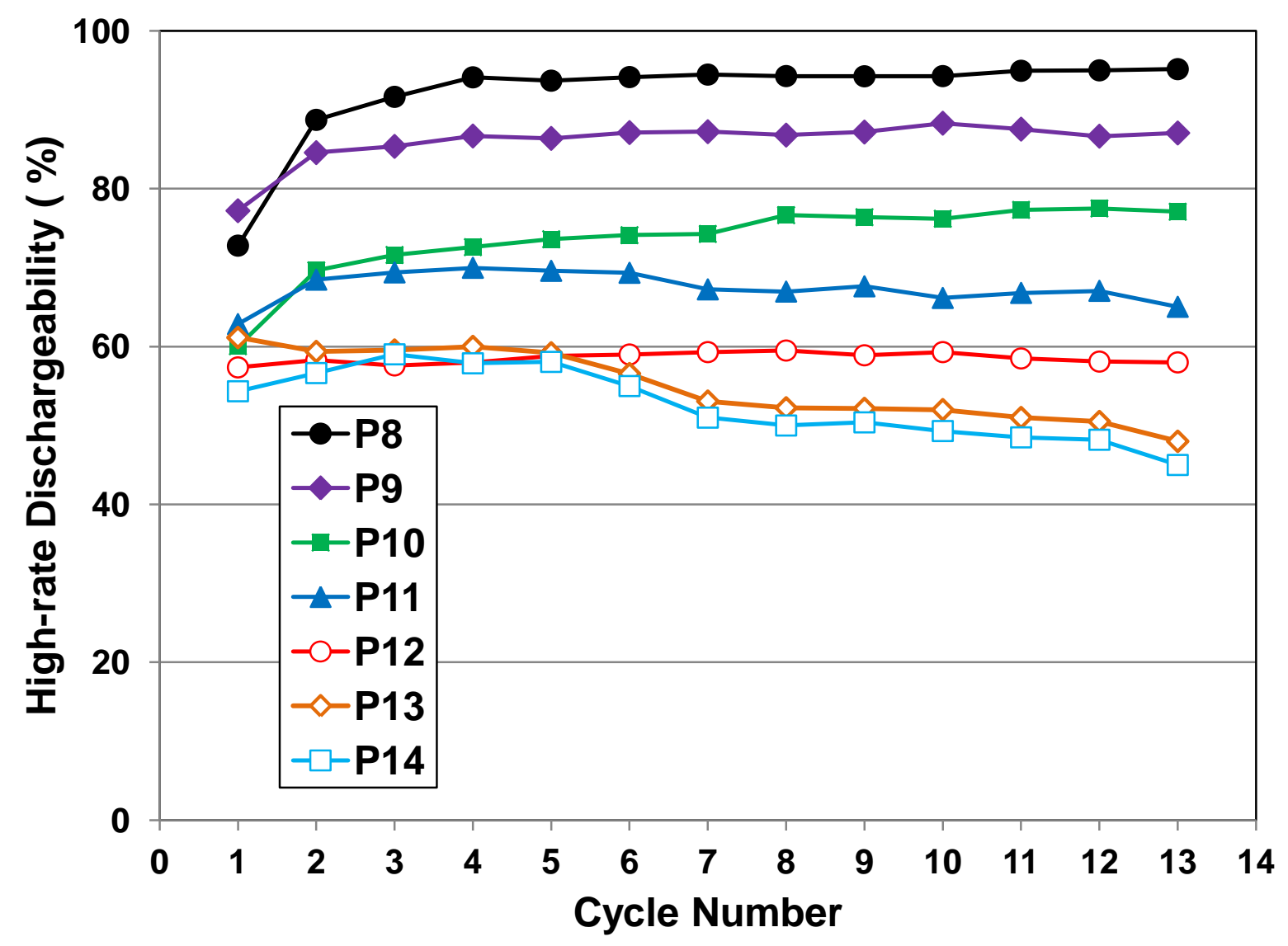

Fig. 7b 


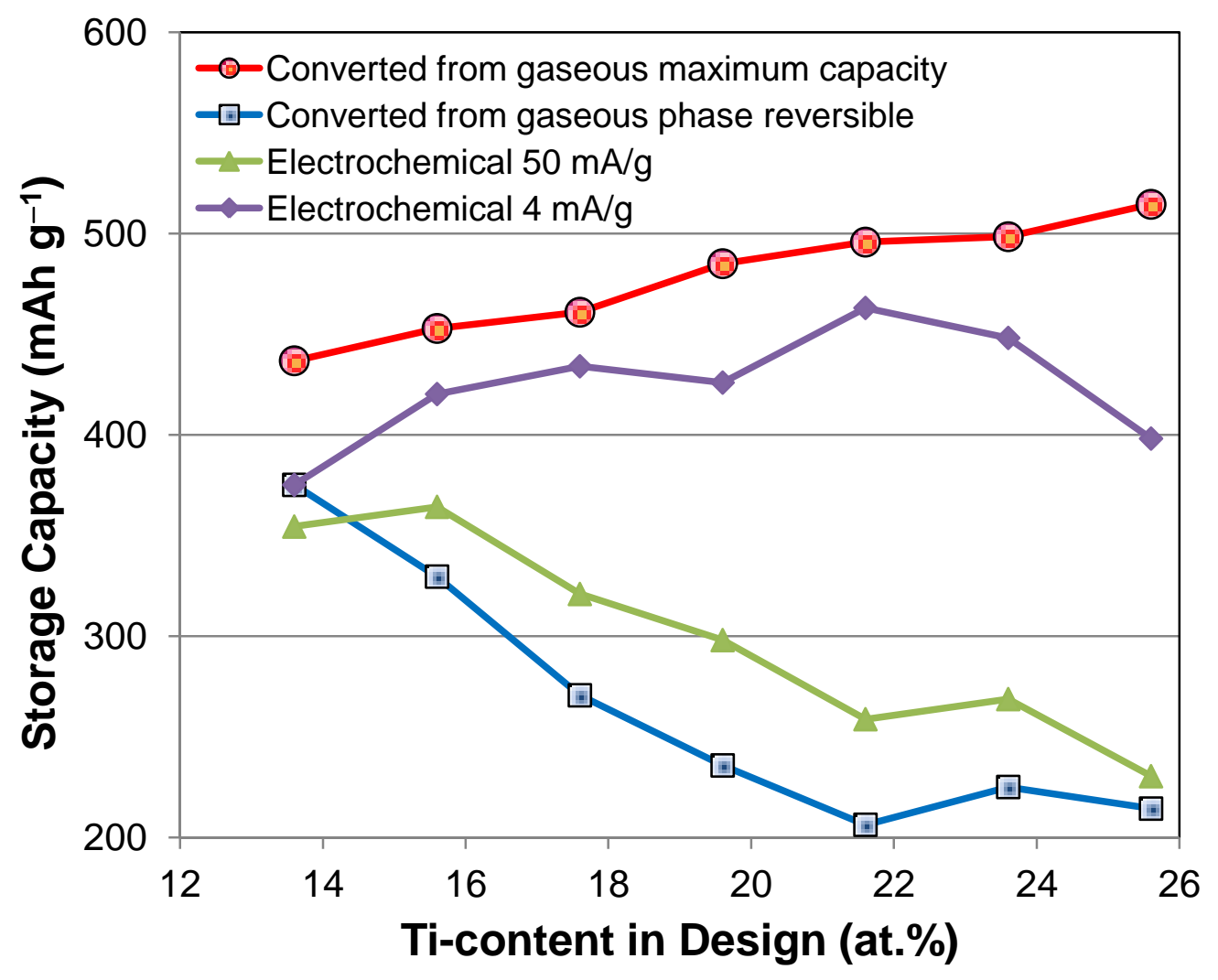

Fig. 8 


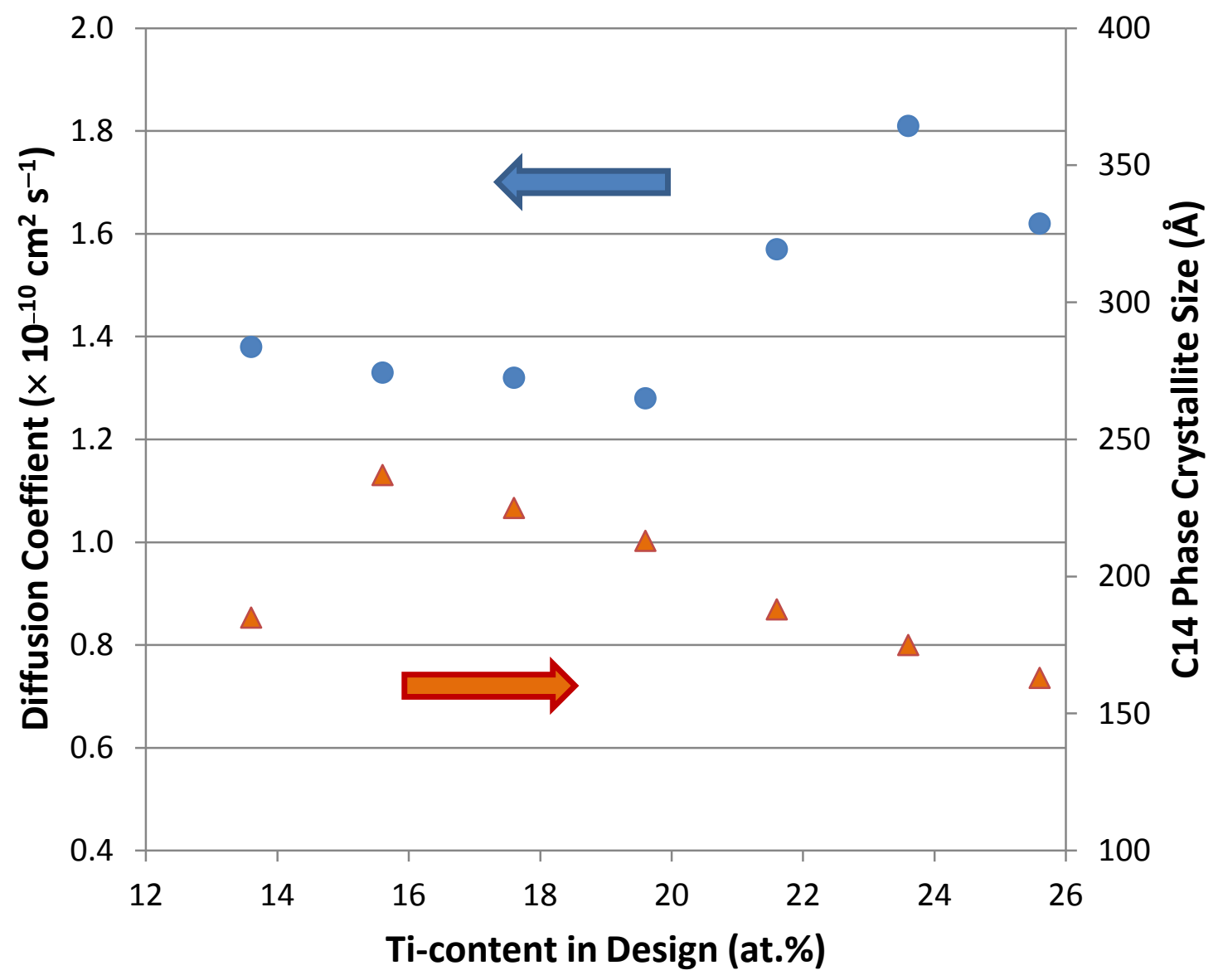

Fig. 9 